\title{
On the ice nucleation spectrum
}

\author{
D. Barahona \\ Global Modeling and Assimilation Office, NASA Goddard Space Flight Center, Greenbelt, Maryland, USA \\ I.M. Systems Group Inc., Rockville, Maryland, USA \\ Correspondence to: D. Barahona (donifan.o.barahona@nasa.gov)
}

Received: 5 October 2011 - Published in Atmos. Chem. Phys. Discuss.: 2 November 2011

Revised: 16 March 2012 - Accepted: 4 April 2012 - Published: 24 April 2012

\begin{abstract}
This work presents a novel formulation of the ice nucleation spectrum, i.e. the function relating the ice crystal concentration to cloud formation conditions and aerosol properties. The new formulation is physically-based and explicitly accounts for the dependency of the ice crystal concentration on temperature, supersaturation, cooling rate, and particle size, surface area and composition. This is achieved by introducing the concepts of ice nucleation coefficient (the number of ice germs present in a particle) and nucleation probability dispersion function (the distribution of ice nucleation coefficients within the aerosol population). The new formulation is used to generate ice nucleation parameterizations for the homogeneous freezing of cloud droplets and the heterogeneous deposition ice nucleation on dust and soot ice nuclei. For homogeneous freezing, it was found that by increasing the dispersion in the droplet volume distribution the fraction of supercooled droplets in the population increases. For heterogeneous ice nucleation the new formulation consistently describes singular and stochastic behavior within a single framework. Using a fundamentally stochastic approach, both cooling rate independence and constancy of the ice nucleation fraction over time, features typically associated with singular behavior, were reproduced. Analysis of the temporal dependency of the ice nucleation spectrum suggested that experimental methods that measure the ice nucleation fraction over few seconds would tend to underestimate the ice nuclei concentration. It is shown that inferring the aerosol heterogeneous ice nucleation properties from measurements of the onset supersaturation and temperature may carry significant error as the variability in ice nucleation properties within the aerosol population is not accounted for. This work provides a simple and rigorous ice nucleation framework where theoretical predictions, labora-
\end{abstract}

tory measurements and field campaign data can be reconciled, and that is suitable for application in atmospheric modeling studies.

\section{Introduction}

Aerosol emissions impact the formation of ice and mixedphase clouds by modifying the background concentration of ice-forming particles (e.g. Rosenfeld and Woodley, 2000; DeMott et al., 2003a; Pratt et al., 2009; Prenni et al., 2009; Lohmann and Feichter, 2005; IPCC, 2007; Barahona et al., 2010; Hoose et al., 2010). Satellite retrievals suggest that cloud condensation nuclei ( $\mathrm{CCN}$ ) emissions may decrease the average size of cloud droplets and "delay" homogeneous ice nucleation in convective clouds (Rosenfeld and Woodley, 2000; Ramanathan et al., 2001). Ice nuclei (IN) emissions may lead to enhanced competition between homogeneous and heterogeneous ice nucleation reducing the ice crystal concentration in cirrus clouds (Barahona et al., 2010; Kärcher et al., 2006; DeMott et al., 1994). IN emissions can also increase the cloud glaciation temperature in mixedphase clouds leading to enhanced precipitation (Lohmann, 2002; Lohmann and Diehl, 2006; Diehl et al., 2007). Accounting for these effects in atmospheric modeling studies requires a link between the ice crystal number concentration, cloud formation conditions (i.e. saturation ratio with respect to ice, $S_{\mathrm{i}}$, and temperature, $T$ ) and the aerosol physicochemical properties. Such relation is usually termed the "ice nucleation spectrum", $N_{\mathrm{c}}\left(S_{\mathrm{i}}, T, \mu_{1 \ldots \mathrm{n}}\right)$ (where $\mu_{1 \ldots \mathrm{n}}$ represent the moments of the distribution of aerosol number concentration) (Barahona and Nenes, 2009; Pruppacher and Klett, 1997). Laboratory and field campaign data have been 
used extensively to generate expressions for $N_{\mathrm{c}}\left(S_{\mathrm{i}}, T, \mu_{1 \ldots \mathrm{n}}\right)$ (e.g. DeMott et al., 2010; Meyers et al., 1992; Phillips et al., 2008; Murray et al., 2011; Welti et al., 2009; Möhler et al., 2006; Vali, 1994), however theoretical prediction of $N_{\mathrm{c}}\left(S_{\mathrm{i}}, T, \mu_{1 \ldots \mathrm{n}}\right)$ remains a challenge.

Classical nucleation theory (CNT) is often used to calculate the nucleation rate coefficient, which when integrated over the appropriate time scale gives $N_{\mathrm{c}}\left(S_{\mathrm{i}}, T, \mu_{1 \ldots \mathrm{n}}\right)$ (e.g. Khvorostyanov and Curry, 2004; Liu and Penner, 2005; Hoose et al., 2010; Chen et al., 2008; Pruppacher and Klett, 1997; Barahona and Nenes, 2009). CNT-based models are usually associated with the so-called "stochastic hypothesis" (Pruppacher and Klett, 1997), where all particles in the aerosol population are assumed to have the same ice nucleation probability. Application of this approach to the homogeneous freezing of liquid droplets has shown agreement with experimental results (e.g. Khvorostyanov and Sassen, 1998; Liu and Penner, 2005; Koop et al., 2000). However, for heterogeneous ice nucleation it provides only a rough approximation to the ice nucleation properties of ambient aerosol (Marcolli et al., 2007; Murray et al., 2011; Lüönd et al., 2010) and often requires empirical constraints to reproduce observations (Eidhammer et al., 2009; Phillips et al., 2008; DeMott et al., 2010).

The assumptions behind CNT however do not require that all particles in an aerosol population should have the same heterogeneous ice nucleation probability, just that all surfaces of the same composition and structure do (Kashchiev, 2000). In fact, due to the heterogeneity of ambient particles, some variation in the particle surface properties within an aerosol population may be expected. This has been recognized in recent studies. For example, Marcolli et al. (2007) found good agreement between theoretical predictions and laboratory results when the heterogeneous nucleation rate coefficient, $J_{\text {het }}$, was averaged over a distribution of contact angles. Working along this line, Niedermeier et al. (2011) and Broadley et al. (2012) developed models where besides a contact angle distribution, the dependency of $N_{\mathrm{c}}\left(S_{\mathrm{i}}, T, \mu_{1 \ldots \mathrm{n}}\right)$ on active site area and the external mixing of IN were considered. In these models the surface of each particle is assumed to be divided into smooth "patches" where $J_{\text {het }}$ is locally defined. Using this approach Broadley et al. (2012) reproduced experimentally observed dependencies of $N_{\mathrm{c}}\left(S_{\mathrm{i}}, T, \mu_{1 \ldots \mathrm{n}}\right)$ on cooling rate, time and temperature in immersion freezing. These models however require the knowledge of the area of each surface patch and of the intra- and inter-particle distributions of surface composition, which may be difficult to constraint, limiting their applicability in cloud studies.

A different approach based on the "singular hypothesis" (Vali, 2008, 1994; Pruppacher and Klett, 1997, and references therein), relies on the existence of active sites on the surface of the IN where ice nucleation occurs at some characteristic $T$ and $S_{\mathrm{i}}$, leading to a time-independent $N_{\mathrm{c}}\left(S_{\mathrm{i}}, T, \mu_{1 \ldots \mathrm{n}}\right)$ (Pruppacher and Klett, 1997). The lack of temporal dependency of $N_{\mathrm{c}}\left(S_{\mathrm{i}}, T, \mu_{1 \ldots \mathrm{n}}\right)$ found in several studies (Möhler et al., 2006; Broadley et al., 2012; Connolly et al., 2009; Vali, 2008) supports this this view. However a theory describing the nature of the active sites that allows the prediction of their characteristic $T$ and $S_{\mathrm{i}}$ is yet to be formulated and $N_{\mathrm{c}}\left(S_{\mathrm{i}}, T, \mu_{1 \ldots \mathrm{n}}\right)$ is generally fitted to limited experimental results. Furthermore, ice nucleation does not occur instantaneously and the singular hypothesis must be understood as an asymptotic approximation to rapid ice nucleation around the characteristic $T$ and $S_{\mathrm{i}}$.

Vali $(2008,1994)$ proposed a hybrid singular-stochastic approach for immersion freezing where the IN follow approximately singular behavior but there is scatter in the observed freezing point due to fluctuations in the ice-embryo size. This model however does not specify how the main freezing point and the width of the dispersion around it should be determined. Niedermeier et al. (2011) and Broadley et al. (2012) showed that even if the nucleation process is fundamentally stochastic, $N_{\mathrm{c}}\left(S_{\mathrm{i}}, T, \mu_{1} \ldots \mathrm{n}\right)$ may approximate singular behavior due to surface composition variability.

There is currently no formulation of the ice nucleation spectrum capable of explaining all the observed features of ice nucleation within a physically-based framework. This work addresses this issue by introducing a novel formulation of $N_{\mathrm{c}}\left(S_{\mathrm{i}}, T, \mu_{1 \ldots \mathrm{n}}\right)$ which instead of using a mechanistic approximation of the surface structure of the IN, relies on a statistical view of the ice nucleation process. The new formulation is physically-based and explicitly considers the effects of supersaturation, temperature, cooling rate, and aerosol size and surface area, on the ice crystal number concentration. This is achieved by introducing the concepts of ice nucleation coefficient and ice nucleation probability dispersion. The new formulation is applied to generate parameterizations of $N_{\mathrm{c}}\left(S_{\mathrm{i}}, T, \mu_{1 \ldots \mathrm{n}}\right)$ for the homogeneous freezing of cloud droplets and the heterogeneous nucleation of ice on dust and soot IN in the deposition mode.

\section{General theory}

In this section the concepts of ice nucleation coefficient and ice nucleation probability dispersion are introduced and used to develop a general relation for the aerosol ice nucleation fraction, $f_{\mathrm{f}}$ (i.e. the fraction of particles that nucleate ice). Nucleation theory is then used to link $f_{\mathrm{f}}$ to measurable quantities such as $T$ and $S_{\mathrm{i}}$ and to derive the homogeneous and heterogeneous ice nucleation spectra.

We start by introducing the ice nucleation coefficient, $\varphi$, i.e., the number of ice germs present within the volume, or on the surface of an aerosol particle. The probability of ice nucleation, $P_{\mathrm{f}}$, is heuristically related to $\varphi$ by (Pruppacher and Klett, 1997)

$P_{\mathrm{f}}=1-e^{-\varphi}$ 
Equation (1) can be extended to describe ice nucleation in an aerosol population by finding the weighted average value of $P_{\mathrm{f}}$,

$$
f_{\mathrm{f}}=1-\int_{0}^{\infty} n(\varphi) e^{-\varphi} \mathrm{d} \varphi
$$

where $n(\varphi)$ is the distribution function of $\varphi$, and describes the number fraction of particles in the aerosol population with nucleation coefficients between $\varphi$ and $\varphi+\mathrm{d} \varphi$. Thus, Eq. (2) represents the sum of the contribution of each $\varphi$ class to the overall aerosol ice nucleation fraction.

The dependency of $f_{\mathrm{f}}$ on $S_{i}, T$ and the physicochemical properties of the aerosol population is found by relating $\varphi$ to the "characteristic" nucleation coefficient, $\bar{\varphi}$, chosen to be a chemically homogeneous particle with properties (composition and size) equal to the average properties of the aerosol population at $S_{i}$ and $T$.

Making $\xi=\frac{\varphi}{\bar{\varphi}}$, Eq. (2) can be written as,

$$
f_{\mathrm{f}}=1-\int_{0}^{\infty} n(\xi) e^{-\xi \bar{\varphi}} \mathrm{d} \xi
$$

where $n(\xi) \mathrm{d} \xi=n(\varphi) \mathrm{d} \varphi$ has been used (i.e., the number concentration of particles in each $\varphi$ class must be equal in the $\xi$ and $\varphi$ spaces). The function $n(\xi)$ is termed the "Nucleation Probability Dispersion Function" (NPDF), and describes the deviation of $\varphi$ from $\bar{\varphi}$ in each particle of the aerosol population.

It can be noticed immediately from Eq. (3) that

$f_{\mathrm{f}}=1-\mathcal{N}(\bar{\varphi})$

where $\mathcal{N}(\bar{\varphi})$ is the Laplace transform of $n(\xi) . \mathcal{N}(\bar{\varphi})$ and $n(\xi)$ are equivalent representations of the NPDF (Medhi, 1994). Thus $f_{\mathrm{f}}$ contains all the information on the underlying distribution of nucleation coefficients (and vice-versa), hence of nucleation probability, in the aerosol population.

$\mathcal{N}(\bar{\varphi})$ for gamma, sectional and lognormal NPDFs is shown in Table 1. For the Lognormal distribution $\mathcal{N}(\bar{\varphi})$ is approximated using $\mathcal{N}(\bar{\varphi}) \propto \int_{0}^{1 / \bar{\varphi}} n(\xi) \mathrm{d} \xi$ (Rossberg, 2008) which is accurate to within $5 \%$ for $\sigma_{\varphi}>3$, when compared against the direct numerical solution of Eq. (3) (not shown). Complex materials may exhibit multimodal NPDFs for which $n(\xi)$ must be modified accordingly (Sect. 3.2.4). In the general case of a sectional NPDF calculation of $\mathcal{N}(\bar{\varphi})$ involves a discrete approximation to the Laplace transform (Table 1) (Shortle et al., 2003).

The ice nucleation spectrum is calculated directly from $f_{\mathrm{f}}$,

$N_{\mathrm{c}}\left(S_{\mathrm{i}}, T, \mu_{1 \ldots \mathrm{n}}\right)=N_{\mathrm{a}} f_{\mathrm{f}}\left[\bar{\varphi}\left(S_{\mathrm{i}}, T, \mu_{1 \ldots \mathrm{n}}\right)\right]$

where $N_{\mathrm{a}}$ is the aerosol number concentration.

\subsection{Definition of $\bar{\varphi}$ and $n(\xi)$}

Equation (4) depends only on $\bar{\varphi}$ and general expressions for $f_{f}$ in terms of $\bar{\varphi}$ can be derived without necessarily knowing the structure of the each particle in the population. Thus, Eq. (4) holds regardless of the ice nucleation mechanism (homogeneous or heterogeneous), or, the interpretation of heterogeneous ice nucleation, e.g. singular vs. stochastic. Its application however requires linking $\bar{\varphi}$ to $S_{\mathrm{i}}, T$ and the aerosol properties; this is accomplished below.

\subsubsection{Homogeneous nucleation}

The homogeneous freezing of cloud droplets and deliquesced aerosol is generally modeled using the homogeneous nucleation rate coefficient, $J_{\text {hom }}$. Comparison of Eq. (1) against Eq. (7.66) of Pruppacher and Klett (1997) suggests that

$\varphi=v_{\mathrm{p}} \int_{0}^{t} J_{\mathrm{hom}} \mathrm{d} t^{\prime}$

where $v_{\mathrm{p}}$ is the particle volume. Equation (6) can be simplified by expanding $\ln J_{\text {hom }}$ into its Taylor series around the current $S_{\mathrm{i}}$ and $T$,

$$
\begin{aligned}
\ln J_{\text {hom }}(t)= & \ln J_{\text {hom }}\left(S_{\mathrm{i}}, T\right)+\frac{\partial \ln J_{\text {hom }}}{\partial S_{\mathrm{i}}}\left[S_{\mathrm{i}}(t)-S_{\mathrm{i}}\right] \\
& +\frac{\partial \ln J_{\mathrm{hom}}}{\partial T}[T(t)-T]+\ldots
\end{aligned}
$$

where the derivatives in Eq. (7) are evaluated at the current $S_{\mathrm{i}}$ and $T$. Taking the exponential of Eq. (7) gives,

$$
J_{\text {hom }}=J_{\text {hom }}\left(S_{\mathrm{i}}, T\right) \exp \left(\frac{\partial \ln J_{\text {hom }}}{\partial S_{\mathrm{i}}} \epsilon_{S_{\mathrm{i}}}+\frac{\partial \ln J_{\mathrm{hom}}}{\partial T} \epsilon_{T}+\ldots\right)
$$

where $\epsilon_{S_{\mathrm{i}}}=S_{\mathrm{i}}(t)-S_{\mathrm{i}}$ and $\epsilon_{T}=T(t)-T$ are perturbations in $S_{i}$ and $T$, respectively. Introducing the last expression into Eq. (6) we obtain,

$$
\begin{aligned}
v_{\mathrm{p}} \int_{0}^{t} J_{\text {hom }} \mathrm{d} t^{\prime}= & v_{\mathrm{p}} J_{\text {hom }}\left(S_{\mathrm{i}}, T\right) \int_{0}^{t} \\
& \exp \left(\frac{\partial \ln J_{\text {hom }}}{\partial S_{\mathrm{i}}} \epsilon_{S_{\mathrm{i}}}+\frac{\partial \ln J_{\text {hom }}}{\partial T} \epsilon_{T}+\ldots\right) \mathrm{d} t^{\prime}
\end{aligned}
$$

using Eq. (9) and making $\tau_{\text {nuc }}=$ $\int_{0}^{t} \exp \left(\frac{\partial \ln J_{\text {hom }}}{\partial S_{\mathrm{i}}} \epsilon_{S_{\mathrm{i}}}+\frac{\partial \ln J_{\text {hom }}}{\partial T} \epsilon_{T}+\ldots\right) \mathrm{d} t^{\prime}$, Eq. (6) becomes

$\varphi=v_{\mathrm{p}} J_{\mathrm{hom}} \tau_{\mathrm{nuc}}$

where $\tau_{\text {nuc }}$ is termed the "nucleation timescale". In general $\tau_{\text {nuc }}$ depends on the predominant nucleation mechanism, $T$, 
$S_{\mathrm{i}}$ and the cooling rate (Barahona and Nenes, 2008). Introducing $\tau_{\text {nuc }}$ in the form of Eq. (10) simplifies the mathematical treatment of $\varphi$, particularly when $S_{i}$ and $T$ change during ice nucleation (Sect. 3.1.1).

Using as characteristic state a homogeneous droplet with the composition and size equal to the mean of the droplet population (Sect. 2) we obtain,

$\xi=\frac{v_{\mathrm{p}} J_{\mathrm{hom}} \tau_{\mathrm{nuc}}}{\overline{v_{\mathrm{p}}} \overline{J_{\mathrm{hom}} \tau_{\mathrm{nuc}}}}$

Equation (11) can be simplified by taking into account that $\varphi$ is dominated by $J_{\text {hom }}$ and only linearly dependent on $\tau_{\text {nuc }}$ (Barahona and Nenes, 2008). Thus, to a good approximation,

$\xi=\frac{v_{\mathrm{p}} J_{\mathrm{hom}}}{\overline{v_{\mathrm{p}}} \overline{J_{\mathrm{hom}}}}$

Homogeneous nucleation is a stochastic process (Pruppacher and Klett, 1997) where $J_{\text {hom }}$ is the same in all droplets that have the same composition. If the variation in droplet composition across the population is small (as for example in the case of cloud droplets), then

$\xi=\frac{v_{\mathrm{p}}}{\overline{v_{\mathrm{p}}}}$

Thus for constant droplet composition, variability in $\varphi$ originates only from dispersion in $v_{\mathrm{p}}$ and the NPDF is determined by the droplet number volume distribution (Sect. 3.1).

\subsubsection{Heterogeneous nucleation}

The probability that ice nucleates heterogeneously on the surface of an aerosol particle is usually expressed in terms of the heterogeneous nucleation rate coefficient, $J_{\text {het }}$, or alternatively, in terms of the surface density of active sites, $\rho_{\text {as }}$. $J_{\text {het }}$ and $\rho_{\text {as }}$ are locally defined and can vary over the surface of each particle as well as among particles in the aerosol population (Niedermeier et al., 2011; Zobrist et al., 2007; Broadley et al., 2012). Taking into account that ice nucleation can be initiated either by the presence of an active site or by stochastic adsorption of water molecules (e.g., Vali, 1994), a mechanistic approximation of $\varphi$ can be written in the form,

$\varphi=s_{\mathrm{p}}\left(\rho_{\mathrm{as}}+\sum_{\mathrm{k}=1}^{\mathrm{N}} \frac{s_{\mathrm{k}}}{s_{\mathrm{p}}} \int_{0}^{t} J_{\mathrm{het}, \mathrm{k}} \mathrm{d} t^{\prime}\right)$

where $s_{\mathrm{p}}$ is the particle surface area. Equation (14) is obtained by assuming that the particle surface is divided into $N$ "smooth patches" of constant composition, with area $s_{\mathrm{k}}$ and local nucleation rate equal to $J_{\text {het,k }}$ (Niedermeier et al., 2011). Equation (14) also accounts for the presence of active sites using $s_{\mathrm{p}}$ as the characteristic length associated with $\rho_{\text {as }}$. If known, the active site surface area (Pruppacher and Klett, 1997; Zobrist et al., 2007) is also suitable to define the contribution to $\varphi$ from nucleation on active sites. It must be noticed that a mechanistic approximation of $\varphi$ is not required to define the NPDF and it is only used to investigate its physical significance.

The NPDF can be obtained from Eq. (4) by choosing as characteristic state a particle with area $\bar{s}_{\mathrm{p}}$ and composition equal to the bulk mean of the aerosol population. It is assumed that ice nucleation at the characteristic state occurs only through surface adsorption, implying that $\bar{\varphi}$ is timedependent. Several reasons justify this assumption. Experimental studies in immersion freezing have reported temporal dependency of $N_{\mathrm{c}}\left(S_{\mathrm{i}}, T, \mu_{1 \ldots \mathrm{n}}\right)$ (e.g., Broadley et al., 2012). Also robust, time-dependent models (e.g., CNT) exist to describe ice nucleation, however only empirical correlations (which are typically obtained using aerosol samples of unknown heterogeneity) are available for $\rho_{\text {as }}$. Finally, even if nucleation on active sites occurs very rapidly, it is still timedependent. Thus, expressing nucleation on active sites in terms $J_{\text {het }}$ (Fletcher, 1969; Pruppacher and Klett, 1997; Marcolli et al., 2007) would simplify the mathematical description of $\varphi$ (Eq. 17). Notice that even if $\bar{\varphi}$ is time-dependent, the NPDF may be such that on average the temporal dependency of $f_{\mathrm{f}}$ vanishes (Sect. 4.3.2).

Based on the above description, $\bar{\varphi}$ can be written as,

$\bar{\varphi}=\overline{s_{\mathrm{p}}} \int_{0}^{t} J_{\text {het }} \mathrm{d} t^{\prime}$

Combining Eqs. (14) and (15) we obtain

$\xi=\frac{s_{\mathrm{p}}\left(\rho_{\mathrm{as}}+\sum_{\mathrm{k}=1}^{\mathrm{N}} \frac{s_{\mathrm{k}}}{s_{\mathrm{p}}} \int_{0}^{t} J_{\mathrm{het}, \mathrm{k}} \mathrm{d} t^{\prime}\right)}{\overline{s_{\mathrm{p}}} \int_{0}^{t} J_{\text {het }} \mathrm{d} t^{\prime}}$

where $J_{\text {het }}$ in Eqs. (15) and (16) is evaluated at the mean aerosol properties. Equation (16) can be simplified by assuming that each active site is associated with a patch of surface area with contact angle close to $0^{\circ}$ (Fletcher, 1969),

$\xi \approx \frac{s_{\mathrm{p}}\left(\sum_{\mathrm{k}=1}^{L} \frac{s_{\mathrm{k}}}{s_{\mathrm{p}}} \int_{0}^{t} J_{\mathrm{het}, \mathrm{k}} \mathrm{d} t^{\prime}\right)}{\overline{s_{\mathrm{p}}} \int_{0}^{t} J_{\text {het }} \mathrm{d} t^{\prime}}$

where $L$ is the total number of surface area patches in each particle, including active sites. Further simplification can be achieved by recognizing that $\sum_{\mathrm{k}=1}^{\mathrm{L}} \frac{s_{\mathrm{k}}}{s_{\mathrm{p}}} J_{\text {het, } \mathrm{k}}$ is simply the weighted average of $J_{\text {het, } \mathrm{k}}$ over the particle surface, i.e.

$$
\int_{0}^{t} J_{\text {het, } \mathrm{p}} \mathrm{d} t^{\prime}=\sum_{\mathrm{k}}^{L} \frac{s_{\mathrm{k}}}{s_{\mathrm{p}}} \int_{0}^{t} J_{\text {het, } \mathrm{k}} \mathrm{d} t^{\prime}
$$


where $J_{\text {het,p }}$ is the "particle effective" nucleation rate coefficient. Introducing the last expression into Eq. (17) we obtain,

$\xi \approx \frac{s_{\mathrm{p}} \int_{0}^{t} J_{\text {het, } \mathrm{p}} \mathrm{d} t^{\prime}}{\overline{s_{\mathrm{p}}} \int_{0}^{t} J_{\mathrm{het}} \mathrm{d} t^{\prime}}$

Equation (19) indicates that if $J_{\text {het,p }}$ is the same in all particles of the aerosol population, then dispersion in $\varphi$ originates only from variation in the particle surface area and the NPDF is determined by the number area distribution.

\section{Application}

\subsection{Homogeneous freezing of cloud droplets}

Aerosol emissions impact the cloud droplet size distribution altering the cloud glaciation temperature and the cold generation of precipitation (Rosenfeld and Woodley, 2000; Ramanathan et al., 2001). It is therefore important to determine how the droplet volume distribution and the cooling rate play a role in determining $f_{\mathrm{f}}$ in cloud droplets. Austin et al. (1995) suggested that the droplet volume distribution can be adequately represented by,

$n(\xi)=\frac{(1+v)^{1+v}}{\Gamma(1+v)} \xi^{v} e^{-(1+v) \xi}$

where $\xi=\frac{v_{\mathrm{p}}}{\bar{v}_{\mathrm{p}}}$ and $v$ is related to the relative variance of the droplet volume distribution (varr $=[7(v+1)]^{-1}$ Austin et al., 1995). Using Table 1 with $\bar{\varphi}=\bar{v}_{\mathrm{p}} J_{\text {hom }} \tau_{\text {nuc }}$ and making $\alpha=$ $\beta=(v+1)$, we obtain

$\mathcal{N}(\bar{\varphi})=\left(\frac{\bar{v}_{\mathrm{p}} J_{\mathrm{hom}} \tau_{\mathrm{nuc}}}{(1+v)}+1\right)^{-(1+v)}$

\subsubsection{Nucleation time scale}

During an experiment at constant $S_{\mathrm{i}}$ and $T$, Eq. (6) is readily integrated to give

$\bar{\varphi}=\bar{v}_{\mathrm{p}} J_{\mathrm{hom}} \Delta t_{\mathrm{exp}}$

where $\Delta t_{\exp }$ is the experimental time of observation. During cloud formation $\tau_{\text {nuc }}$ (Eq. 10) must be used instead as $T, S_{\mathrm{i}}$ vary during nucleation.

To develop an expression for $\tau_{\text {nuc }}$ it is advantageous to write $\int_{0}^{t} J_{\text {hom }} \mathrm{d} t^{\prime}$ in terms of $\partial T / \partial t$ and $\partial S_{\mathrm{w}} / \partial t$, being $S_{\mathrm{w}}$ the saturation ratio with respect to water, i.e.,

$$
\int_{0}^{t} J_{\text {hom }} \mathrm{d} t=\int_{T}^{T_{0}} \frac{J_{\text {hom }}}{\frac{\partial T^{\prime}}{\partial t}} \mathrm{~d} T^{\prime}+\int_{S_{\text {isat }}}^{S_{\mathrm{w}}} \frac{J_{\text {hom }}}{\frac{\partial S_{\mathrm{w}}^{\prime}}{\partial t}} \mathrm{~d} S_{\mathrm{w}}^{\prime}
$$

where $T_{0}=273 \mathrm{~K}, S_{\mathrm{w}}^{\text {isat }}=p_{\mathrm{s}, \mathrm{i}} / p_{\mathrm{s}, \mathrm{w}}$ is the value of $S_{\mathrm{w}}$ at $S_{\mathrm{i}}=$ 1 , and $p_{\mathrm{s}, \mathrm{w}}$ and $p_{\mathrm{s}, \mathrm{i}}$ are the liquid water and ice saturation vapor pressures at $T$, respectively (Murphy and Koop, 2005). Taking into account that for the droplet population $S_{\mathrm{w}} \approx 1$ and $\mathrm{d} S_{\mathrm{w}} \approx 0$, Eq. (23) can be simplified to

$\int_{0}^{t} J_{\text {hom }} \mathrm{d} t^{\prime}=\int_{T_{0}}^{T} \frac{J_{\text {hom }}}{\gamma} \mathrm{d} T^{\prime}$

where $\gamma=-\frac{\partial T}{\partial t}$ is the cooling rate, assumed constant during nucleation. Using Eq. (8), the last expression can be written as

$\int_{0}^{t} J_{\text {hom }} \mathrm{d} t^{\prime}=\frac{J_{\text {hom }}}{\gamma} \int_{T_{0}}^{T} \exp \left(\frac{\partial \ln J_{\text {hom }}}{\partial T} \epsilon_{T}+\ldots\right) \mathrm{d} T^{\prime}$

Over the small $T$ interval in which ice nucleation occurs (typically about $2 \mathrm{~K}$, Fig. 2) $\frac{\mathrm{d} \ln \mathrm{J}_{\mathrm{hom}}}{\mathrm{d} T}$ is almost constant (Barahona and Nenes, 2008) and the high order derivatives of $\ln J_{\text {hom }}$ vanish. Using this, and taking into account that $J_{\text {hom }}$ decreases steeply with $T$, Eq. (25) can be simplified to

$\int_{0}^{t} J_{\text {hom }} \mathrm{d} t^{\prime} \approx \frac{J_{\text {hom }}}{\gamma} \int_{T}^{T-\epsilon_{T}} \exp \left(\frac{\partial \ln J_{\text {hom }}}{\partial T} \epsilon_{T}^{\prime}\right) \mathrm{d} T^{\prime}$

where $\epsilon_{T}=T(t)-T$. Since $\mathrm{d} T=\mathrm{d} \epsilon_{T}$, Eq. (26) can be written as

$\int_{0}^{t} J_{\text {hom }} \mathrm{d} t^{\prime} \approx \frac{J_{\text {hom }}}{\gamma} \int_{0}^{-\epsilon_{T}} \exp \left(\frac{\partial \ln J_{\text {hom }}}{\partial T} \epsilon_{T}^{\prime}\right) \mathrm{d} \epsilon_{T}^{\prime}$

Solving the integral in Eq. (27) and using $\exp \left(-\frac{\partial \ln J_{\text {hom }}}{\partial T} \epsilon_{T}\right) \ll 1 \quad$ (Barahona and Nenes, 2008) we obtain,

$\int_{0}^{t} J_{\text {hom }} \mathrm{d} t \approx-\frac{J_{\text {hom }}}{\frac{\partial \ln J_{\text {hom }}}{\partial T} \gamma}$

Using the chain rule, $\frac{\partial \ln J_{\text {hom }}}{\partial T}=\left[\frac{\mathrm{d} \ln J_{\text {hom }}}{\mathrm{d} S_{\mathrm{w}}} \frac{\mathrm{d} S_{\mathrm{w}}}{\mathrm{d} T}\right]_{S_{\mathrm{w}}=1}$ where $J_{\text {hom }}$ is given by the parameterization of Koop et al. (2000). From Murphy and Koop (2005), $\left[\frac{\mathrm{d} S_{\mathrm{w}}}{\mathrm{d} T}\right]_{S_{\mathrm{w}}=1}=-6132.9 / T^{2}$ $\mathrm{K}$. Introducing this into Eq. (28) it can be readily seen that $\tau_{\text {nuc }}=\left(-\frac{\partial \ln J_{\text {hom }}}{\partial T} \gamma\right)^{-1}=\left(\frac{6132.9 \gamma}{T^{2}} \frac{\mathrm{d} \ln J_{\text {hom }}}{\mathrm{d} S_{\mathrm{w}}}\right)^{-1}$. Collecting terms into Eq. (21) we obtain the final expression for homogeneous ice nucleation in cloud droplets,

$\mathcal{N}(\bar{\varphi})=\left[\frac{\bar{v}_{\mathrm{p}} J_{\mathrm{hom}}\left(\frac{6132.9 \gamma}{T^{2}} \frac{\mathrm{d} \ln J_{\mathrm{hom}}}{\mathrm{d} S_{\mathrm{w}}}\right)^{-1}}{(1+v)}+1\right]^{-(1+v)}$ 


\subsection{Heterogeneous ice nucleation in the deposition mode}

Ice nucleation by direct adsorption of water vapor onto the aerosol surface is termed deposition ice nucleation. This process is thought to significantly impact the formation of cirrus at low $T$ (Barahona et al., 2010; Hoose et al., 2010; Möhler et al., 2006). Weakly wettable species like soot may also nucleate ice in this mode at higher $T$ than required for cirrus formation, potentially impacting the formation of mixedphase clouds (Seisel et al., 2005). Currently only CNT provides sufficient detail to allow the calculation of $J_{\text {het }}$ over a wide range of conditions and is therefore used here to derive $\bar{\varphi}$ for deposition ice nucleation.

\subsubsection{Ice nucleation rate coefficient}

Within the framework of CNT, $J_{\text {het }}$ is given by (Pruppacher and Klett, 1997; Kashchiev, 2000),

$J_{\text {het }}=Z_{\text {het }} c_{1, \mathrm{~s}} \beta_{\mathrm{h}} \exp \left(-\frac{\Delta g_{\mathrm{g}}}{k T}\right)$

where $Z_{\text {het }}$ is the Zeldovich factor, $c_{1, \mathrm{~s}}$ is the surface concentration of water molecules, $\beta_{\mathrm{h}}$ is the rate at which water molecules are incorporated into the critical ice cluster, and $k$ is the Boltzmann constant. The remaining term in Eq. (30) is the energy of formation of the ice germ, given by (Pruppacher and Klett, 1997)

$\Delta g_{\mathrm{g}}=f \frac{4 \pi}{3} \sigma_{\mathrm{i} / \mathrm{v}} r_{\mathrm{g}}^{2}$

where $\sigma_{\mathrm{i} / \mathrm{v}}$ is the surface tension of ice $\left(106 \mathrm{~mJ} \mathrm{~m}^{-2}\right.$ Pruppacher and Klett, 1997), and $r_{\mathrm{g}}$ is the ice germ size given by,

$r_{\mathrm{g}}=\frac{2 v_{\mathrm{w}} \sigma_{\mathrm{i} / \mathrm{v}}}{k T \ln S_{\mathrm{i}}}$

where $v_{\mathrm{w}}$ is the volume of a water molecule (Zobrist et al., 2007).

The compatibility parameter, $f$, in Eq. (31) accounts for the reduction in the work of ice formation caused by the heterogeneous surface (Kashchiev, 2000). It is given by

$f=\frac{1}{4}(2+\cos \theta)(1-\cos \theta)^{2}$

where $\theta$ is the local contact angle between the solid surface and the ice germ (Pruppacher and Klett, 1997). In writing Eq. (33) it is assumed that the substrate has planar geometry. Given the complex geometry of atmospheric particles (e.g. Dymarska et al., 2006; Zimmermann et al., 2008) it is not clear whether assuming a spherical substrate (or any other simple geometry) would represent a better approximation to $f$ than Eq. (33). Therefore curvature effects are not considered. Misfit strain can reduce $J_{\text {het }}$ (Khvorostyanov and
Curry, 2004; Pruppacher and Klett, 1997) however current parameterizations depend on largely unconstrained parameters and such effects are not considered.

Despite the simplicity of Eq. (30) calculation of $J_{\text {het }}$ is subject to uncertainty. The form of $Z_{\mathrm{het}}, c_{1, \mathrm{~s}}$, and $\beta_{\mathrm{h}}$ depends on whether the ice germ grows by direct incorporation of water molecules from the vapor phase or they first adsorb onto the particle surface and then diffuse to the ice germ. The value of $c_{1, \mathrm{~s}}$ is also strongly influenced by the formation of water monolayers on the particle surface (Määttänen et al., 2005; Seisel et al., 2005). Määttänen et al. (2005) have shown that these factors may introduce up to a factor of two uncertainty in $f_{\mathrm{f}}$.

The steady-state surface concentration is determined by equilibrium between the incoming and outgoing molecule fluxes (Pruppacher and Klett, 1997),

$c_{1, s}=\frac{\alpha_{\mathrm{c}} p_{v}}{v_{s} \sqrt{2 \pi m_{w} k T}} \exp \left(\frac{\Delta g_{d}}{k T}\right)$

where $\Delta g_{\mathrm{d}}$ is the desorption energy of water molecules from the particle surface, $p_{\mathrm{v}}$ the water vapor pressure, $v_{\mathrm{S}}$ the molecular frequency of vibration $\left(10^{13} \mathrm{~s}^{-1}\right)$, and $m_{\mathrm{w}}$ the mass of a water molecule $\left(2.99 \times 10^{-26} \mathrm{~kg}\right.$ ) (Pruppacher and Klett, 1997). The mass accommodation coefficient, $\alpha_{\mathrm{c}}$, has been introduced into Eq. (34) to account for the low sticking efficiency of the water vapor molecules onto the particle surface (it is assumed that $\alpha_{\mathrm{c}}=1.0$ for the ice surface) (Pruppacher and Klett, 1997; Seisel et al., 2005). Assuming direct water vapor deposition onto the ice germ (which typically results in a conservative estimate of $J_{\text {het }}$ ) gives (Määttänen et al., 2005),

$J_{\text {het }}=\frac{\alpha_{\mathrm{c}}}{\sqrt{f}} \frac{p_{\mathrm{v}}^{2} v_{\mathrm{w}}}{m_{\mathrm{w}} k T v_{\mathrm{s}}} \sqrt{\frac{\sigma_{\mathrm{i} / \mathrm{v}}}{k T}} \exp \left(\frac{\Delta g_{\mathrm{d}}}{k T}\right) \exp \left(-\frac{\Delta g_{\mathrm{g}}}{k T}\right)$

Equation (35) resembles Eq. (11) of Chen et al. (2008), however in Eq. (35) $f$ is raised to the $-1 / 2$ power instead of $1 / 2$; the latter results from neglecting the effect of the solid surface on $r_{\mathrm{g}}$ (Vehkamäki et al., 2007). The expression of Chen et al. may however lead to unphysical behavior as it implies that $J_{\text {het }} \rightarrow 0$ when $f \rightarrow 0$ (i.e. ice nucleation would be more difficult on easily wettable materials). The authors also suggested that $\Delta g_{\mathrm{d}}$ is similar to the activation energy of water molecules in immersion freezing. However whereas increasing $\Delta g_{\mathrm{d}}$ leads to low desorption rates increasing $c_{1, \mathrm{~s}}$ (Eq. 34) hence $J_{\text {het }}$, increasing the activation energy leads to a decrease in $J_{\text {het }}$ (Pruppacher and Klett, 1997).

Equation (35) can be written in the form

$J_{\text {het }}=A \exp \left(-\frac{\Delta g_{\mathrm{g}}}{k T}\right)$

where $A=\frac{\alpha_{\mathrm{c}}}{\sqrt{f}} \frac{p_{\mathrm{v}}^{2} v_{\mathrm{w}}}{m_{\mathrm{w}} k T v_{\mathrm{s}}} \sqrt{\frac{\sigma_{\mathrm{i} / v}}{k T}} \exp \left(\frac{\Delta g_{\mathrm{d}}}{k T}\right)$. Typical values of $A$ range between $10^{23}$ and $10^{26} \mathrm{~m}^{-2} \mathrm{~s}^{-1}$. 


\subsubsection{Nucleation time scale}

For ice nucleation in the deposition mode the relative variation in $S_{\mathrm{w}}$ is significantly larger than the relative variation in $T$ (Barahona and Nenes, 2009), i.e. $\frac{1}{S_{\mathrm{w}}} \frac{\mathrm{d} S_{\mathrm{w}}}{\mathrm{d} t} \gg \frac{1}{T} \frac{\mathrm{d} T}{\mathrm{~d} t}$. Equation (23) can then be approximated as,

$$
\int_{0}^{t} J_{\text {het }} \mathrm{d} t^{\prime}=\int_{S_{\mathrm{w}}^{\text {isat }}}^{S_{\mathrm{w}}} \frac{J_{\mathrm{het}}}{\frac{\partial S_{\mathrm{w}}}{\partial t}} \mathrm{~d} S_{\mathrm{w}}^{\prime}
$$

Using $\frac{\partial S_{\mathrm{W}}}{\partial t} \approx \alpha_{\mathrm{s}} u$ (Barahona and Nenes, 2009), where $u$ is the vertical velocity and $\alpha_{\mathrm{s}}=\frac{g \Delta H_{\mathrm{s}} m_{\mathrm{W}}}{c_{\mathrm{p}} k T^{2}}-\frac{g m_{\mathrm{a}}}{k T}, g$ is the acceleration of gravity, $\Delta H_{\mathrm{s}}$ the latent heat of sublimation of ice (Pruppacher and Klett, 1997), and $c_{\mathrm{p}}$ and $m_{\mathrm{a}}$ are the heat capacity and molecular mass of air, respectively, Eq. (37) becomes,

$$
\int_{0}^{t} J_{\text {het }} \mathrm{d} t=\frac{1}{\alpha_{S} u} \int_{S_{\mathrm{w}}^{\text {isat }}}^{S_{\mathrm{w}}} J_{\mathrm{het}} \mathrm{d} S_{\mathrm{w}}^{\prime}
$$

Replacing $J_{\text {hom }}$ for $J_{\text {het }}$ into Eq. (8) and introducing the result into Eq. (38) we obtain

$$
\int_{0}^{t} J_{\text {het }} \mathrm{d} t^{\prime}=\frac{J_{\text {het }}}{\alpha_{s} u} \int_{S_{\mathrm{w}}^{\text {isat }}}^{S_{\mathrm{w}}} \exp \left(\frac{\partial \ln J_{\text {het }}}{\partial S_{\mathrm{W}}} \epsilon_{S_{\mathrm{w}}}+\ldots\right) \mathrm{d} S_{\mathrm{w}}^{\prime}
$$

where $\epsilon_{S_{\mathrm{w}}}=S_{\mathrm{w}}(t)-S_{\mathrm{w}}$. For small variation in $S_{\mathrm{w}}, \frac{\partial \ln J_{\mathrm{het}}}{\partial S_{\mathrm{w}}}$ is almost constant (Barahona and Nenes, 2009) and the high order derivatives of $\ln J_{\text {het }}$ vanish. With this Eq. (39) becomes,

$$
\int_{0}^{t} J_{\text {het }} \mathrm{d} t^{\prime}=\frac{J_{\text {het }}}{\alpha_{S} u} \int_{S_{\mathrm{w}}^{\text {isat }}}^{S_{\mathrm{w}}} \exp \left(\frac{\partial \ln J_{\text {het }}}{\partial S_{\mathrm{w}}} \epsilon_{S_{\mathrm{w}}}\right) \mathrm{d} S_{\mathrm{w}}^{\prime}
$$

Taking into account that $J_{\text {het }}$ is a steep function of $S_{\mathrm{W}}$ (Sect. 4.3) and that $J_{\text {het }}=0$ for $S_{\mathrm{w}}=S_{\mathrm{w}}^{\text {isat }}$ the lower limit of integration in Eq. (40) can be replaced by $S_{\mathrm{w}}-\epsilon_{S_{\mathrm{w}}}$. Using this, and making $\mathrm{d} S_{\mathrm{w}}=\mathrm{d} \epsilon S_{\mathrm{w}}$ into Eq. (40) we obtain

$$
\int_{0}^{t} J_{\text {het }} \mathrm{d} t^{\prime}=\frac{J_{\text {het }}}{\alpha_{S} u} \int_{-\epsilon_{S_{\mathrm{w}}}}^{0} \exp \left(\frac{\partial \ln J_{\text {het }}}{\partial S_{\mathrm{w}}} \epsilon_{S_{\mathrm{w}}}^{\prime}\right) \mathrm{d} \epsilon_{S_{\mathrm{w}}}^{\prime}
$$

Further simplification can be achieved by noticing that most of the variability in $J_{\text {het }}$ comes from the exponential term in Eq. (36). Therefore to a good approximation we can write

$$
\frac{\partial \ln J_{\mathrm{het}}}{\partial S_{\mathrm{W}}} \approx-\frac{1}{k T} \frac{\partial \Delta g_{\mathrm{g}}}{\partial r_{\mathrm{g}}} \frac{\partial r_{\mathrm{g}}}{\partial S_{\mathrm{w}}}
$$

To calculate $\frac{\partial r_{\mathrm{g}}}{\partial S_{\mathrm{w}}}$ is convenient to write $r_{\mathrm{g}}$ in terms of $S_{\mathrm{w}}$. Making $S_{\mathrm{W}}=S_{\mathrm{i}}\left(p_{\mathrm{s}, \mathrm{i}} / p_{\mathrm{s}, \mathrm{w}}\right)$, replacing into Eq. (32) and rearranging we obtain,

$r_{\mathrm{g}} \approx \frac{r_{\mathrm{g}}^{\circ}}{1+\frac{S_{\mathrm{w}}-1}{\ln \left(p_{\mathrm{s}, \mathrm{i}} / p_{\mathrm{s}, \mathrm{w}}\right)}}$

Where $r_{\mathrm{g}}^{\circ}=\left.r_{\mathrm{g}}\right|_{S_{\mathrm{w}}=1}$ and $\ln \left(S_{\mathrm{W}}\right) \approx S_{\mathrm{W}}-1$ has been used. Taking the derivative with respect to $S_{\mathrm{W}}$ in Eqs. (31) and (43), replacing into Eq. (42), and rearranging we obtain,

$\frac{\partial \ln J_{\text {het }}}{\partial S_{\mathrm{W}}} \approx \frac{f n_{\mathrm{g}}^{\circ}}{\left(1+\frac{S_{\mathrm{W}}-1}{\ln \left(p_{\mathrm{s}, \mathrm{i}} / p_{\mathrm{s}, \mathrm{w}}\right)}\right)^{3}}$

where $n_{\mathrm{g}}^{\circ}=\frac{4 \pi}{3} \frac{\left(r_{\mathrm{g}}^{\circ}\right)^{3}}{v_{\mathrm{w}}}$ is the number of water molecules in the ice germ at water saturation. The second term in the denominator of Eq. (44) is typically negligible compared to 1, and Eq. (44) can be approximated as

$\frac{\partial \ln J_{\text {het }}}{\partial S_{\mathrm{w}}} \approx f n_{\mathrm{g}}^{\circ}$

Introducing the last result into Eq. (41) gives,

$\int_{0}^{t} J_{\text {het }} \mathrm{d} t^{\prime}=\frac{J_{\text {het }}}{\alpha_{s} u} \int_{-\epsilon_{S_{\mathrm{w}}}}^{0} \exp \left(f n_{\mathrm{g}}^{\circ} \epsilon_{S_{\mathrm{w}}}^{\prime}\right) \mathrm{d} \epsilon_{S_{\mathrm{w}}}^{\prime}$

Integrating the last expression, and since typically $\exp \left(-f n_{\mathrm{g}}^{\circ} \epsilon_{S_{\mathrm{w}}}\right) \ll 1$, Eq. (15) can be written as

$\bar{\varphi}=\overline{s_{\mathrm{p}}} J_{\text {het }}\left(\frac{1}{\alpha_{\mathrm{s}} u f n_{\mathrm{g}}^{\circ}}\right)=s_{\mathrm{p}} J_{\text {het }} \tau_{\text {nuc }}$

where $\tau_{\text {nuc }}=\left(\alpha_{\mathrm{s}} u f n_{\mathrm{g}}^{\circ}\right)^{-1}$.

\subsubsection{The nature of $n(\xi)$ in deposition ice nucleation}

The mechanistic approximation of $\varphi$ presented in Sect. 2.1.2 can be used to investigate the functional form of the NPDF. Using Eq. (47) into Eq. (19), and since most of the variability in $\varphi$ comes from $J_{\text {het, }}$, we can write,

$\xi \approx \frac{s_{\mathrm{p}} J_{\text {het,p }}}{\overline{s_{\mathrm{p}}} \overline{J_{\text {het }}}}$

Using Eqs. (31), (35) and (48), and taking into account that most of the variation in $J_{\text {het,p }}$ results from variation in the exponential term of Eq. (36), we obtain for the NPDF

$n(\xi)=n\left(\frac{s_{\mathrm{p}}}{\bar{s}_{\mathrm{p}}} e^{-\Delta g_{\mathrm{g}}^{\circ}\left(f\left(\theta_{p}\right)-f(\bar{\theta})\right)}\right)$ 
Table 1. $\mathcal{N}(\bar{\varphi})$ and $n(\xi)$ for gamma, lognormal and sectional NPDFs; $\bar{\varphi}$ is the characteristic ice nucleation coefficient defined in Sect. 2.1, $\Gamma$ is the gamma function, and $f_{\mathrm{a}, k}$ represents the fraction of the aerosol population with cumulative ice nucleation probability below $1-$ $\exp \left(-\xi_{k} \bar{\varphi}\right)$. The lognormal $\mathcal{N}(\bar{\varphi})$ is approximated using $\mathcal{N}(\bar{\varphi}) \propto \int_{0}^{1 / \bar{\varphi}} n(\xi) \mathrm{d} \xi(\operatorname{Rossberg}, 2008)$.

\begin{tabular}{lcc}
\hline Distribution & $n(\xi)$ & $\mathcal{N}(\bar{\varphi})$ \\
\hline Gamma & $\frac{\beta^{\alpha}}{\Gamma(\alpha)} \xi^{\alpha-1} e^{-\beta \xi}$ & $\left(\frac{\beta}{\bar{\varphi}+\beta}\right)^{\alpha}$ \\
\hline \multirow{2}{*}{ Lognormal } & $\frac{e^{-\frac{\ln ^{2}(\xi)}{2 \sigma_{\varphi}^{2}}}}{\sqrt{2 \pi} \sigma_{\varphi} \xi}$ & $\frac{1}{2} \operatorname{erfc}\left(\frac{\ln (\bar{\varphi})}{\sqrt{\pi} \sigma_{\varphi}}\right)$ \\
\hline Sectional & $\frac{f_{\mathrm{a}, k}-f_{\mathrm{a}, k-1}}{\xi_{k}-\xi_{k-1}}$ & $\sum_{i} p_{i} e^{-\bar{\varphi} \xi_{i}}$ where $p_{i}=\int_{\xi_{i-1}}^{\xi_{i+1}} n(\xi) \mathrm{d} \xi$ \\
\hline
\end{tabular}

where $\theta_{p}$ is the "particle effective" contact angle associated with $J_{\text {het,p }}$ (Eq. 19), $\bar{\theta}$ is the contact angle associated with $\bar{\varphi}$, and $\Delta g_{\mathrm{g}}^{\circ}=\left.\Delta g_{\mathrm{g}}\right|_{\theta=180^{\circ}}$. Expanding $f\left(\theta_{p}\right)$ into its Taylor series around $\bar{\theta}$ and neglecting the high order derivatives of $f$ gives,

$n(\xi) \approx n\left(\frac{s_{\mathrm{p}}}{\bar{s}_{\mathrm{p}}} e^{-\left.\Delta g_{\mathrm{g}}^{\circ} \frac{\mathrm{d} f}{\mathrm{~d} \theta}\right|_{\bar{\theta}}\left(\theta_{p}-\bar{\theta}\right)}\right)$

which can be written as

$n(\xi)=n\left(\frac{s_{\mathrm{p}}}{\bar{s}_{\mathrm{p}}} e^{c\left(\theta_{p}-\bar{\theta}\right)}\right)$

where $c=-\left.\Delta g_{\mathrm{g}}^{\circ} \frac{\mathrm{d} f}{\mathrm{~d} \theta}\right|_{\bar{\theta}}$. If all particles in the population have the same surface area, the NPDF reduces to

$n(\xi)=n\left(e^{c\left(\theta_{p}-\bar{\theta}\right)}\right)$

Equation (52) suggests that $n(\xi)$ for heterogeneous ice nucleation follows a lognormal distribution. If $\theta_{p}-\bar{\theta}$ follows a normal distribution with variance $\sigma_{\theta}^{2}$ (i.e. the particle surface composition is randomly determined), then $\xi=$ $\exp \left(c\left(\theta_{p}-\bar{\theta}\right)\right)$ follows a lognormal distribution with variance $c^{2} \sigma_{\theta}^{2}$ (this can be shown by making $\frac{\ln \xi}{c}=\left(\theta_{p}-\bar{\theta}\right)$ ). At the limit of constant $\theta_{p}$ the number area distribution (which is usually lognormally distributed, Seinfeld and Pandis, 1998) determines $n(\xi)$ (Eq. 19). These two limits of variability in $\varphi$ suggest a lognormal NPDF. Equation (52) also indicates that $\bar{\theta}$ is approximately equal to the mean $\theta_{p}$ of the aerosol population.

\subsubsection{Final form for deposition ice nucleation}

Combining the expressions of Table 1 with Eqs. (4) and (47), a concise expression for $\mathcal{N}(\bar{\varphi})$ can be written in the form,

$\mathcal{N}(\bar{\varphi})=\frac{1}{2} \operatorname{erfc}\left[\frac{\ln \left(\frac{\bar{s}_{\mathrm{p}} J_{\mathrm{het}}}{\alpha_{\mathrm{s}} u f n_{\mathrm{g}}^{\circ}}\right)}{\sqrt{\pi} \sigma_{\varphi}}\right]$ where $f$ and $J_{\text {het }}$ are calculated at the mean aerosol properties, and $\sigma_{\varphi}$ is termed the "ice nucleation dispersion coefficient". Equation (53) shows that given $S_{\mathrm{i}}, T$ and $u, f_{\mathrm{f}}$ depends only on $\bar{s}_{\mathrm{p}}, \sigma_{\varphi}$, and the characteristic contact angle, $\bar{\theta}$ (associated with $\bar{\varphi}$ ). Complex aerosol mixtures may exhibit multimodal NPDFs. Equation (53) can be readily extended to such cases by making,

$\mathcal{N}(\bar{\varphi})=\frac{1}{2} \sum_{i=1}^{M} w_{i} \operatorname{erfc}\left[\frac{\ln \left(\frac{\bar{s}_{\mathrm{p}} J_{\mathrm{het}, i}}{\alpha_{\mathrm{s}} u f_{i} n_{\mathrm{g}}^{\mathrm{g}}}\right)}{\sqrt{\pi} \sigma_{\varphi, i}}\right]$

where $w_{i}$ is the weight of the $i$-th lognormal mode in $n(\xi)$, and $M$ is the total number of modes.

\section{Results and discussion}

\subsection{General behavior of $\mathcal{N}(\bar{\varphi})$}

The probability of observing a nucleation event in an aerosol population increases with $\bar{\varphi}$, i.e. $f_{\mathrm{f}}$ is always a monotonic function of $\bar{\varphi}$. Figure 1 shows $f_{\mathrm{f}}$ for lognormal, gamma, and sectional NPDFs. The width of each NPDF (e.g. $\sigma_{\varphi}, \alpha$, and the standard deviation, $\sigma$, respectively) has been varied over a wide interval and the distribution mean set to $\xi=1$ (Eq. 3). To illustrate the discrete transform approximation method (Table 1, Shortle et al., 2003), the sectional distribution in Fig. 1 (top panels) has been derived from a normal distribution using 20 bins. This method produces a continuous, smooth increasing $f_{\mathrm{f}}$, however using only 20 bins results in smaller sensitivity to $\sigma$ than the analytical transform of $n(\xi)$ (not shown).

The form and width of the NPDF strongly influence $f_{\mathrm{f}}$. As a consequence of the support of the normal distribution between $-\infty$ and $\infty$, nucleation spectra derived from the normal NPDF tend to shift right as $\sigma$ decreases. Indeed, if $\varphi$ is normally distributed then a finite probability of $\varphi<0$ exist, leading to unphysical behavior. As the gamma and lognormal NPDFs have support only on the positive real axis, 

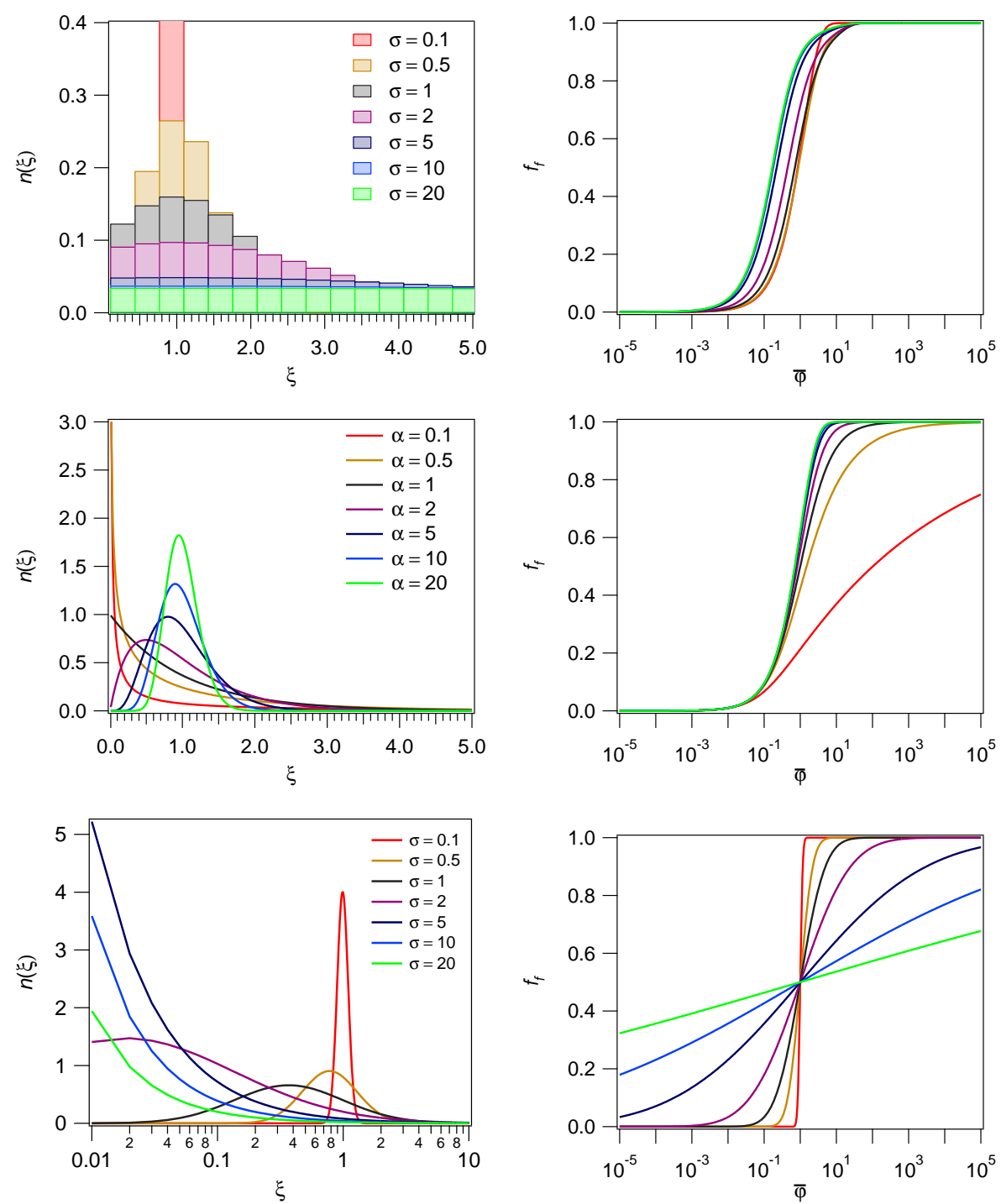

Fig. 1. Ice nucleation probability dispersion functions (left panels) and corresponding ice nucleation fraction (right panels). Shown are sectional (based on a normal distribution using 20 bins, top panels), gamma (middle panels) and lognormal (bottom panels) distributions.
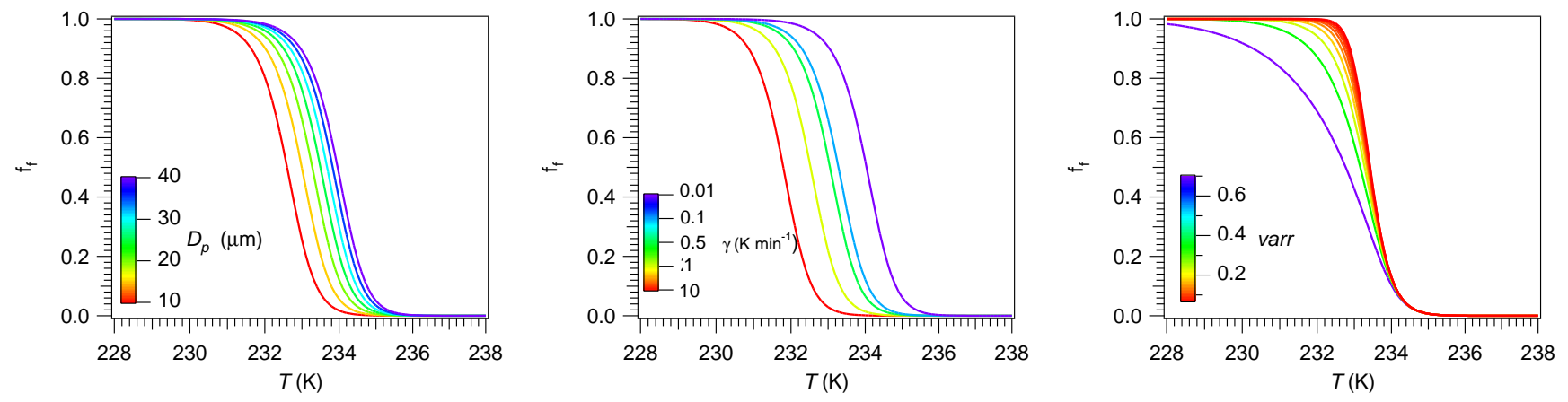

Fig. 2. Homogeneous ice nucleation spectra for the freezing of cloud droplets. Unless otherwise specified $\gamma=-\frac{\mathrm{d} T}{\mathrm{~d} t}=1 \mathrm{~K} \mathrm{~min}^{-1}, D_{\mathrm{p}}=20$ $\mu \mathrm{m}$, and varr $=0.25$. 

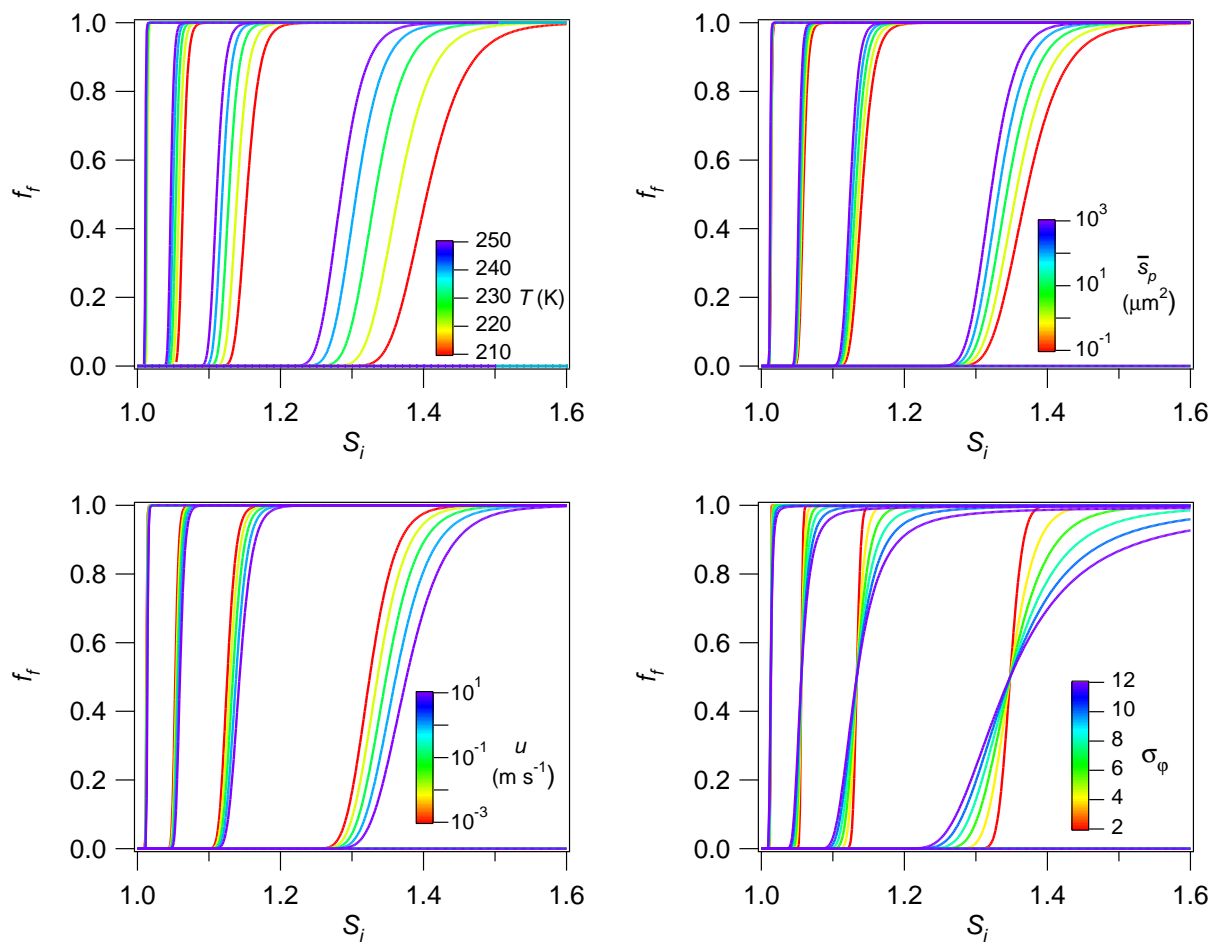

Fig. 3. Heterogeneous ice nucleation spectra in the deposition mode. Lines are grouped by characteristic contact angle, $\bar{\theta}=$ $\left[5^{\circ}, 10^{\circ}, 15^{\circ}, 23^{\circ}\right]$ (from left to right). Unless otherwise specified $u=0.1 \mathrm{~m} \mathrm{~s}^{-1}, \bar{s}_{\mathrm{p}}=5 \mu \mathrm{m}^{2}, \sigma_{\varphi}=5$, and $T=225 \mathrm{~K}$.

values of $\varphi<0$ are not accessible to $\mathcal{N}(\bar{\varphi})$. Thus, the inflection point in the $f_{\mathrm{f}}$ curve (Fig. 1) for these NPDFs is always around $\bar{\varphi}=1$. This means that ice crystal formation becomes significant around the conditions for which there is, on average, one ice germ per particle in the population. $\bar{\varphi}=1$ also defines characteristic values for $J_{\text {het }}$ (or $J_{\text {hom }}$ ) and $\rho_{\text {as }}$. A similar conclusion was reached by Khvorostyanov and Curry (2004) using the empirical constraint of $\bar{s}_{\mathrm{p}} J_{\text {het }} \approx 1 \mathrm{~s}^{-1}$. The theory presented here generalizes this picture and suggests that the characteristic $J_{\text {het }}($ at $\bar{\varphi}=1)$ is found at $f_{\mathrm{f}} \approx 0.5$ instead of the typical $f_{\mathrm{f}} \approx 0.01$ used in experimental studies.

The lognormal and gamma distributions display distinctive behavior to the variation in the width of the NPDF. For the gamma distribution the slope of $f_{\mathrm{f}}$ remains almost constant for $\alpha>0.5$ but decreases steeply for $\alpha<0.5$, which is explained by the larger probability of finding small $\varphi$ at lower $\alpha$ (Fig. 1, left panels). For the lognormal distribution a larger $\sigma_{\varphi}$ leads to a larger probability of both, small and large $\varphi$. The former limits the value of $f_{\mathrm{f}}$ as $\bar{\varphi} \rightarrow \infty$ whereas the latter increases $f_{\mathrm{f}}$ at low $\bar{\varphi}$. These features may explain the low $f_{\mathrm{f}}$ typically observed in ambient aerosol (e.g. Eidhammer et al., 2009; Phillips et al., 2008) and the diversity of ice nucleation thresholds observed in experimental studies. This is further analyzed in Sect. 4.3.3.

\subsection{Homogeneous nucleation}

Figure 2 shows the sensitivity of the nucleation spectrum for homogeneous freezing to $D_{\mathrm{p}}, \gamma$ and varr (Eq. 21). Although Eq. (29) is written in terms of $\bar{v}_{\mathrm{p}}$, the equivalent droplet size, $D_{\mathrm{p}}$, is most often used in experimental studies; they are simply related by $D_{\mathrm{p}}=\left(\frac{6 \bar{v}_{\mathrm{p}}}{\pi}\right)^{1 / 3}$. As $\bar{\varphi}$ scales with $\gamma$ and $D_{\mathrm{p}}$ their variation tends to "shift" $f_{\mathrm{f}}$ along the $T$ axis. Decreasing $D_{\mathrm{p}}$ from $40 \mu \mathrm{m}$ to $10 \mu \mathrm{m}$ decreases $T_{\text {onset }}$ (defined at $\left.f_{\mathrm{f}} \approx 0.01\right)$ from $236 \mathrm{~K}$ to $233 \mathrm{~K}$. Variation in $\gamma$ has the opposite effect although with a weaker impact: a factor of $10^{3}$ increase in $\gamma$ only results in about $3 \mathrm{~K}$ lower $T_{\text {onset }}$ (explained by the decrease in $\tau_{\text {nuc }}$ as $\gamma$ increases, Eq. 27). Thus cooling rate variation may have a limited role in ice crystal production by homogeneous freezing of cloud droplets (although it has an important effect in the homogeneous freezing of liquid aerosol particles (Barahona and Nenes, 2008)).

Homogeneous freezing may be strongly impacted by dispersion in the droplet size distribution. For varr $<0.4$ the slope of $f_{\mathrm{f}}$ remains almost constant and nearly all droplets freeze within $2-3 \mathrm{~K}$ of $T_{\text {onset }}$. However as varr increases beyond $0.4, f_{\mathrm{f}}$ "stretches" over a wider $T$ interval so that at varr $=0.7$ some droplets freeze at $T$ as low as $228 \mathrm{~K}$. This is explained by the decrease in $\alpha$ as varr increases (i.e., varr $\propto \frac{1}{\alpha}$ ) resulting in a larger fraction of small droplets in the population (Sect. 4.1). In other words since $T_{\text {onset }}$ does 

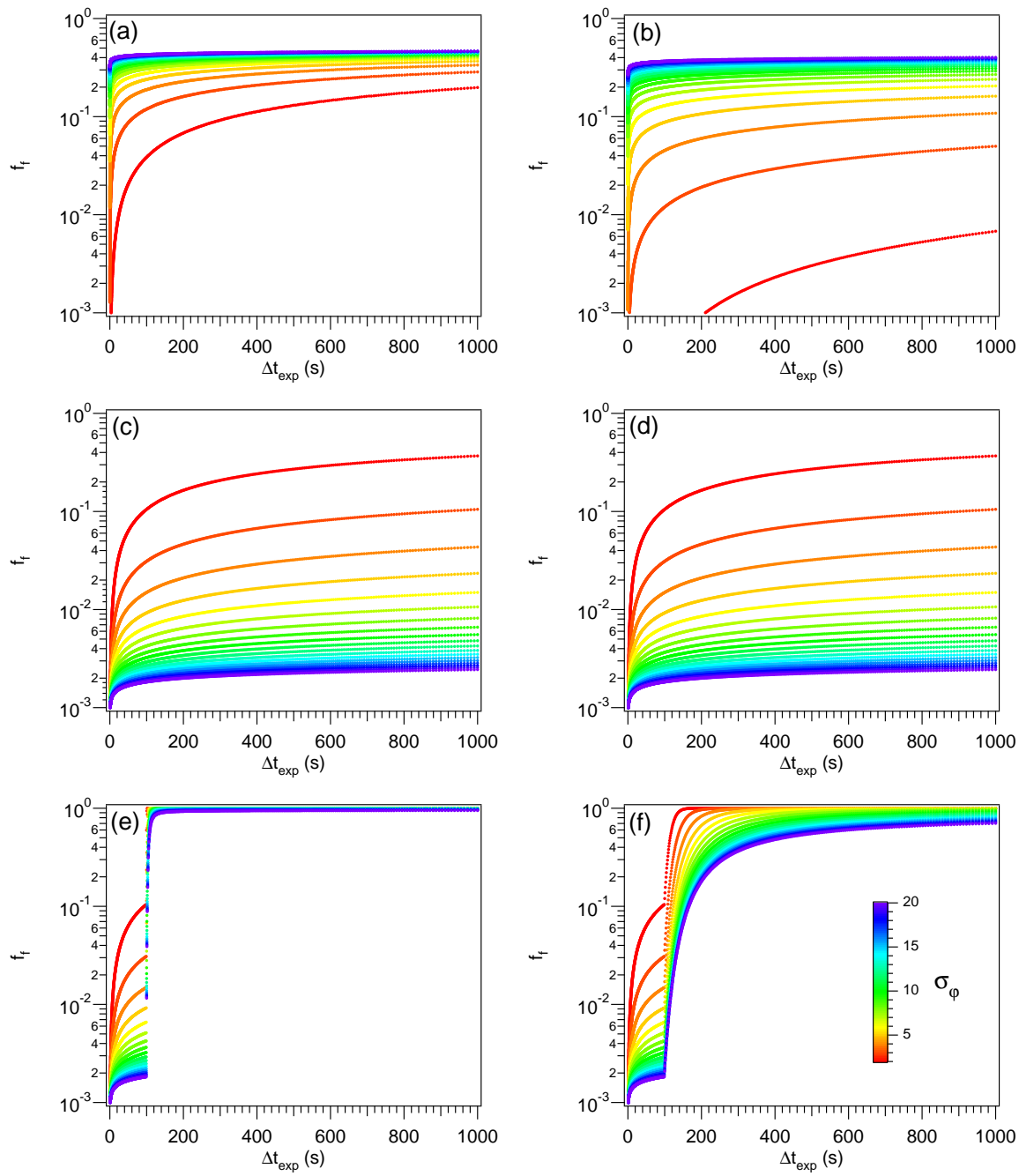

Fig. 4. Ice nucleation fraction vs. observation time at $T=220 \mathrm{~K}$, for IN with $\bar{\theta}=6^{\circ}$ (left panels) and $\bar{\theta}=23^{\circ}$ (right panels). (a) Constant $S_{\mathrm{i}}=1.023$. (b) Constant $S_{\mathrm{i}}=1.345$. (c-d) $S_{\mathrm{i}}$ is increased over $1 \mathrm{~s}$ up to the point where $f_{\mathrm{f}}=0.001$ and then maintained constant afterwards. (e-f) As (c) and (d) but $S_{\mathrm{i}}$ is increased by 0.001 after $\Delta t_{\mathrm{exp}}=100 \mathrm{~s}$. The particle mean surface area was set to $\bar{s}_{\mathrm{p}}=10 \mu \mathrm{m}^{2}$.

not change with increasing varr the stretching effect becomes only obvious if the whole $f_{\mathrm{f}}$ curve is considered. This previously unidentified behavior of homogeneous freezing may have important implications for the development of convective clouds as aerosol emissions and entrainment tend to broaden the droplet size distribution (Pruppacher and Klett, 1997).

\subsection{Heterogeneous ice nucleation in the deposition mode}

\subsubsection{General features}

Figure 3 shows representative profiles of $f_{\mathrm{f}}$ for heterogeneous ice nucleation in the deposition mode. In general $f_{\mathrm{f}}$ is primarily a function of $S_{\mathrm{i}}$ and $\bar{\theta}$, and to a lower extent, of $T, \bar{s}_{\mathrm{p}}, u$ and $\sigma_{\varphi}$. For $\bar{\theta}<10^{\circ}, f_{\mathrm{f}}$ tends to be very steep and almost insensitive to $T, \overline{s_{\mathrm{p}}}, u$ and $\sigma_{\varphi}$. Therefore a single, constant $S_{\mathrm{i} \text {,onset }}$ can be assigned to aerosol populations with low $\bar{\theta}$. This indicates that highly efficient IN tend to display features typically associated with singular behavior (even though a time-dependent approach is used to calculate $\bar{\varphi})$. However this may not imply a lack of temporal dependency of $f_{\mathrm{f}}$ at constant $S_{\mathrm{i}}$ and $T$ (Broadley et al., 2012) and is further analyzed in Sect. 4.3.2.

IN with high $\bar{\theta}$ are strongly influenced by $T, \overline{s_{\mathrm{p}}}$ and $u$. In this regime $f_{\mathrm{f}}$ is also impacted by $\sigma_{\varphi}$ so that variation in the width of the NPDF caused by repeated freezing cycles and by dispersion in surface composition may affect $S_{\mathrm{i}, \text { onset }}$. These characteristics imply that weak IN display features commonly associated with the stochastic hypothesis. Thus within the context of the theory presented here, stochastic 


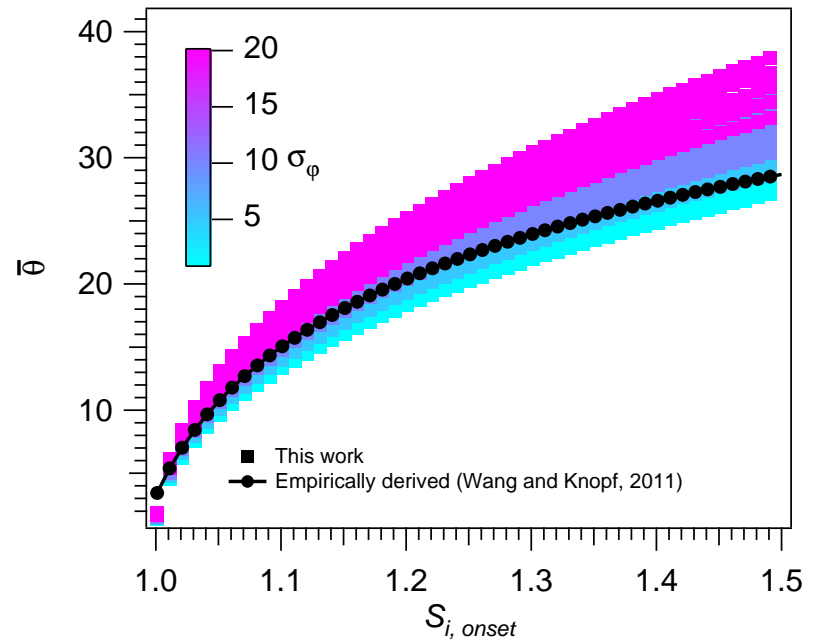

Fig. 5. Correlation between the mean contact angle and $S_{\mathrm{i}}$ at the nucleation onset $\left(f_{\mathrm{f}}=0.01\right)$. $T$ was varied between 200 and $250 \mathrm{~K}$, $u$ between 0.01 and $1 \mathrm{~m} \mathrm{~s}^{-1}$, and $\bar{s}_{\mathrm{p}}$ between 0.1 and $100 \mu \mathrm{m}^{2}$.

and singular features in the ice nucleation spectrum can be understood as limits of variability in the NPDF.

For the highest $\bar{\theta}$ used in Fig. $3\left(23^{\circ}\right)$ decreasing $T$ from $250 \mathrm{~K}$ to $210 \mathrm{~K}$ leads to an increase of 0.15 in $S_{\mathrm{i} \text {,onset }}$ (defined at $f_{\mathrm{f}} \approx 0.01$ ). This is explained by the increase in $r_{\mathrm{g}}$ and $\Delta g_{\mathrm{g}}$ as $T$ decreases lowering $J_{\text {het }}$ (Eq. 30). Increasing $u$ from $10^{-3}$ to $10 \mathrm{~m} \mathrm{~s}^{-1}$ increases $S_{\mathrm{i}, \text { onset }}$ by about 0.1 at $\theta=23^{\circ}$ (Fig. 3, bottom left panels). This is explained by the decrease in $\tau_{\text {nuc }}$ as $u$ increases (Eq. 47) so that higher $J_{\text {het }}$ is required to reach $\bar{\varphi}=1$. Although the sensitivity of $S_{\mathrm{i} \text {,onset }}$ to $u$ is significant, achieving a large variation in $u$ in experimental studies may be technically challenging and the effect of variation in the cooling rate on $f_{f}$ in deposition ice nucleation may be difficult to observe.

$S_{\mathrm{i} \text {,onset }}$ decreases by about 0.08 when $\overline{S_{\mathrm{p}}}$ increases from $0.1 \mu \mathrm{m}^{2}$ to $100 \mu \mathrm{m}^{2}$. Although this is consistent with existing studies (Kanji et al., 2008; Welti et al., 2009) direct comparison against experimental results is difficult as the number area distribution is usually not reported. The range of $\bar{s}_{\mathrm{p}}$ considered in Fig. 3 is however typically observed in ambient aerosol (Eastwood et al., 2008; Dymarska et al., 2006; Kanji et al., 2008) and the effect of $\bar{s}_{\mathrm{p}}$ on $f_{\mathrm{f}}$ may be readily observable in the laboratory.

Increasing $\sigma_{\varphi}$ tends to decrease $S_{\mathrm{i} \text {,onset }}$ as larger $\sigma_{\varphi}$ leads to larger probability of finding high $\varphi$ (Sect. 4.1). This effect is evident for $\bar{\theta}>10^{\circ}$ and indicates that the relation between $S_{\mathrm{i}, \text { onset }}$ and $\bar{\theta}$ (Fig. 5) can be strongly impacted by $\sigma_{\varphi}$. When $\sigma_{\varphi} \rightarrow 0$ (i.e. a very narrow NPDF, Eq. 1) $\bar{\theta}$ and $S_{\mathrm{i} \text {, onset }}$ are related by an exponential function weakly dependent on $T, \overline{s_{\mathrm{p}}}$ and $u$, and close to the solutions of $J_{\text {het }}=\frac{-\ln (0.99)}{\bar{s}_{\mathrm{p}} \tau_{\text {nuc }}}$. A similar functional dependency was found by Wang and Knopf (2011) from measurements of $S_{\mathrm{i} \text {,onset }}$, which was interpreted as a physical dependency of $\bar{\theta}$ on $S_{\mathrm{i}}$. Figure 5 instead indicates that rather than physical dependency the empirical fit of Wang and Knopf represents correlation. Indeed, for $\sigma_{\varphi}>1$, different combinations of $T, \overline{s_{\mathrm{p}}}$ and $u$ result in a family of relations between $\bar{\theta}$ and $S_{\mathrm{i} \text {,onset. }}$.

Figure 5 suggests that the error in $\bar{\theta}$ from neglecting variability in surface properties increases with $S_{\mathrm{i} \text {,onset }}$ and $\sigma_{\varphi}$. Determining $S_{\mathrm{i} \text {,med }}$ (i.e., $S_{\mathrm{i}}$ at $f_{\mathrm{f}}=0.5$ ) instead of $S_{\mathrm{i} \text {,onset }}$ may reduce this error (Fig. 3), however only measurement of the $f_{\mathrm{f}}$ vs. $S_{\mathrm{i}}$ curve provides information on $\sigma_{\varphi}$, and would indicate the existence of multiple modes in the NPDF (Sect. 4.3.3).

\subsubsection{Temporal effects on deposition ice nucleation}

Figure 4 shows $f_{\mathrm{f}}$ for efficient and weak IN $\left(\bar{\theta}=6^{\circ}\right.$ and $\bar{\theta}=23^{\circ}$, respectively) as a function of $\Delta t_{\exp }$ for different values of $S_{\mathrm{i}}$ and constant $T$. For these conditions Eq. (53) is simplified as $\mathcal{N}(\bar{\varphi})=\frac{1}{2} \operatorname{erfc}\left[\frac{\ln \left(\bar{s}_{\mathrm{p}} J_{\text {het }} \Delta t_{\text {exp }}\right)}{\sqrt{\pi} \sigma_{\varphi}}\right]$. Maintaining the efficient IN at $S_{\mathrm{i}}=1.023$ (Fig. 4a) results in significant $f_{\mathrm{f}}$ after a few seconds. For low surface variability $\left(\sigma_{\varphi}<5\right)$ $f_{f}$ keeps increasing over time whereas for $\sigma_{\varphi}>10$ it remains constant after $\Delta t_{\exp }=10 \mathrm{~s}$. This behavior is explained by the larger increase in $\bar{\varphi}$ required to increase $f_{f}$ as $\sigma_{\varphi}$ increases (Eqs. 37 and 53). It is also consistent with the work of Niedermeier et al. (2011) who concluded that increasing variability in surface properties weakens temporal effects. The temporal behavior of $f_{\mathrm{f}}$ is strongly influenced by the value of $S_{\mathrm{i}}$ set during an experiment. Thus maintaining the IN population with $\bar{\theta}=23^{\circ}$ at $S_{\mathrm{i}}=1.023$ results in $f_{\mathrm{f}}=0$ over the whole time interval considered (not shown), and only for $S_{\mathrm{i}}=1.345$ (Fig. $4 \mathrm{~b}$ ) is the temporal dependency of $f_{\mathrm{f}}$ evident.

The value $S_{\mathrm{i}}$ at which temporal effects on $f_{\mathrm{f}}$ become evident may not be known in advance. Thus a more likely $S_{\mathrm{i}}$ trajectory in experimental studies may increase $S_{\mathrm{i}}$ up to a point where $f_{\mathrm{f}}=0.001$, and then maintain it constant afterwards (Figs. 4c and 4d) (e.g. Broadley et al., 2012). For this case IN populations with low $\sigma_{\varphi}$ result in high $f_{\mathrm{f}}$ over the time of the experiment since they start nucleation at higher $S_{\mathrm{i}}$ than IN with higher $\sigma_{\varphi}$. This behavior is opposite to the cases at constant $S_{\mathrm{i}}$ (Figs. $4 \mathrm{a}$ and $4 \mathrm{~b}$ ) where low $\sigma_{\varphi}$ resulted in low $f_{\mathrm{f}}$, and indicates that the $S_{\mathrm{i}}$ trajectory followed in an experiment strongly impacts the observed $f_{\mathrm{f}}$. As before, high $\sigma_{\varphi}$ leads to weak temporal dependency of $f_{\mathrm{f}}$.

High variability in surface properties may not always result in a weak temporal dependency of $f_{\mathrm{f}}$. In Fig. $4 \mathrm{e}$ and 4f the same conditions as in Fig. $4 \mathrm{c}$ and $4 \mathrm{~d}$ are maintained, but $S_{\mathrm{i}}$ is increased by $0.1 \%$ after $\Delta t_{\exp }=100 \mathrm{~s}$. For $\bar{\theta}=6^{\circ}$ (Fig. 4e) this perturbation in $S_{\mathrm{i}}$ rapidly increases $f_{\mathrm{f}}$ which remains constant afterwards. For $\bar{\theta}=23^{\circ}$ (Figs. 4f) a similar increase in $f_{\mathrm{f}}$ occurs after the increase in $S_{\mathrm{i}}$, however for $\sigma_{\varphi}>10$ temporal effects become more evident after the perturbation. The striking feature of Fig. $4 \mathrm{f}$ is that it is the IN 

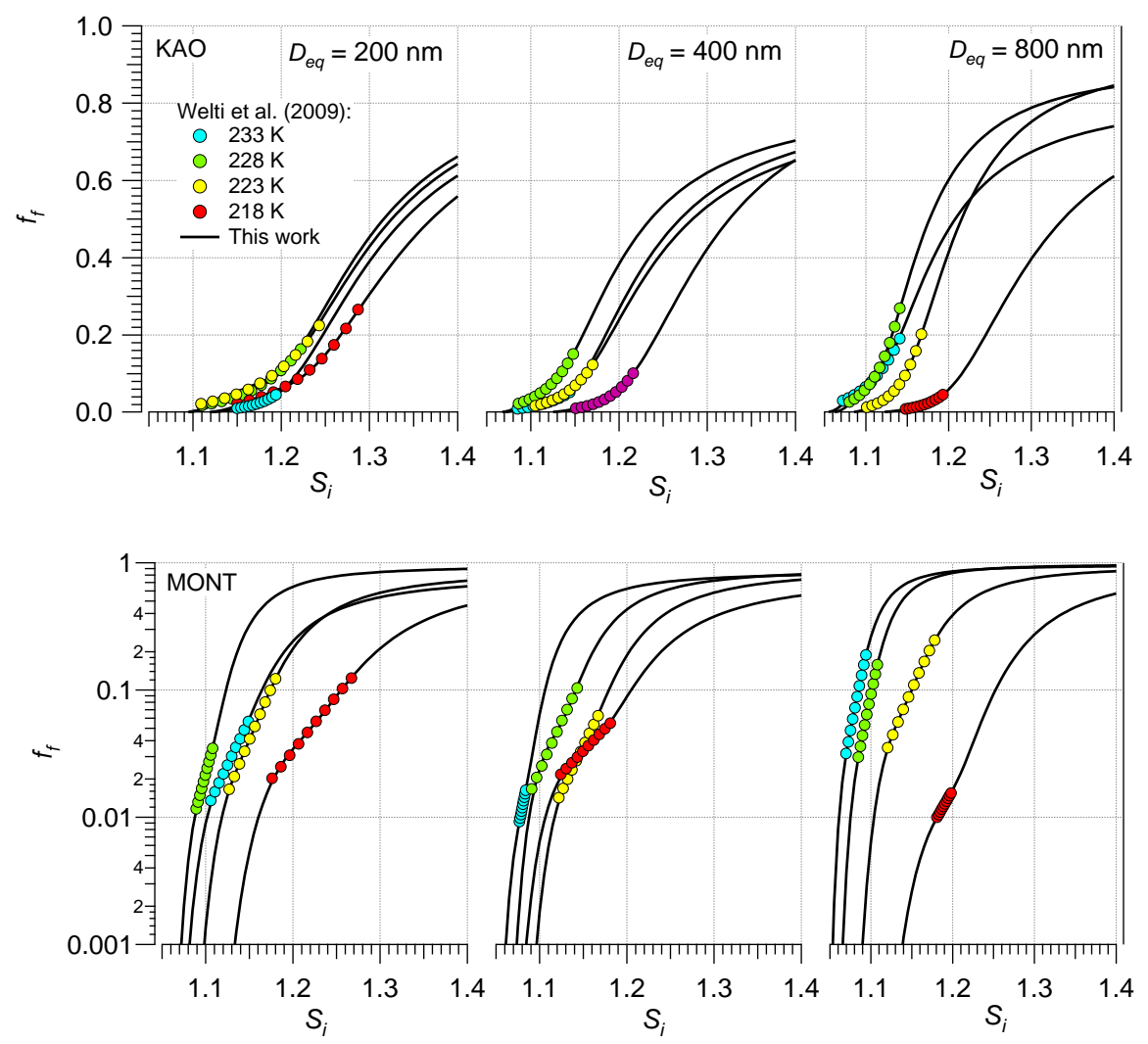

Fig. 6. Heterogeneous ice nucleation spectra in the deposition mode for Kaolinite (KAO) and Montmorillonite (MONT) (Table 2).

with high $\sigma_{\varphi}$ that display significant temporal dependency, contrary to the behavior depicted in Figs. 4a-d. Thus the role of surface variability on the temporal dependency of $f_{\mathrm{f}}$ depends strongly on the $S_{\mathrm{i}}$ trajectory followed. This also indicates that for IN with multimodal NPDF (Sect. 4.3.3) different fractions of the aerosol may display different temporal behavior.

Figure 4 suggests that experimental apparatus with $\Delta t_{\exp }$ of a few seconds would tend to underestimate $f_{\mathrm{f}}$ because only the fraction of the IN that nucleates ice rapidly at the experimentally set $S_{\mathrm{i}}$ would be accounted for. Whether this bias would affect IN with high or low $\sigma_{\varphi}$ depends on the $S_{\mathrm{i}}$ trajectory followed. The magnitude of the underestimation depends on $\sigma_{\varphi}$ but in some cases it may be of several orders of magnitude. This indicates that measurements of IN in cloud chamber experiments with typical residence times of about 10-20 s, would tend to underestimate the IN concentration if the temporal dependency of $N_{\mathrm{c}}\left(S_{\mathrm{i}}, T, \mu_{1 \ldots \mathrm{n}}\right)$ is not accounted for.

Comparison between Figs. 3 and 4 suggests that high sensitivity of $f_{\mathrm{f}}$ to $u$ does not necessarily imply significant temporal dependency of $f_{\mathrm{f}}$. This is because the effect of $u$ on $f_{\mathrm{f}}$ is controlled by $\frac{\mathrm{d} f_{\mathrm{f}}}{\mathrm{d} S_{\mathrm{i}}}$ whereas the temporal dependency of $f_{\mathrm{f}}$ depends on $\sigma_{\varphi}$ and $\bar{s}_{\mathrm{p}} J_{\text {het }}$. Thus $f_{\mathrm{f}}$ for efficient IN may be insensitive to variation in $u$ but still exhibit temporal de- pendency. An vice versa, the $f_{\mathrm{f}}$ of weak IN may not exhibit temporal dependency even if it is susceptible to variation in $u$ (Fig. 3). This is consistent with the study of Broadley et al. (2012) who found that cooling rate and temporal effects on $f_{\mathrm{f}}$ are not correlated. Moreover, since the lack of dependency of $f_{\mathrm{f}}$ on $u$ and time can be reproduced using a time-dependent, stochastic approach, they cannot be considered prove of the singular hypothesis.

\subsubsection{Parameterization of the ice nucleation spectra of dust and soot}

Among the different IN species present in the atmosphere, soot and dust have been identified to play a significant role in the formation of cirrus and mixed-phase clouds (e.g. DeMott et al., 2003a,b; Gayet et al., 2004). The theory presented in Sects. 2 and 3 can be used to analyze empirical ice nucleation spectra and generate parameterizations for usage in atmospheric models, as follows.

\section{Dust}

Several authors have studied the ice nucleation properties of dust (e.g. Eastwood et al., 2008; Zimmermann et al., 2008, and references therein). Although most studies focus on measuring $S_{\mathrm{i} \text {, onset }}$, the works of Möhler et al. (2006, M06) 
Table 2. Parameters of the nucleation spectra derived from the data reported by Möhler et al. (2006, M06), Welti et al. (2009, W09), and Crawford et al. (2011, C11); $\sigma_{\varphi}$ is assumed to be the same in all modes.

\begin{tabular}{|c|c|c|c|c|c|c|c|c|c|c|}
\hline \multirow[t]{2}{*}{ Species } & \multirow[t]{2}{*}{ Reference } & \multirow[t]{2}{*}{$\bar{s}_{\mathrm{p}}\left(\mu \mathrm{m}^{2}\right)$} & \multirow[t]{2}{*}{$T(\mathrm{~K})$} & \multicolumn{2}{|c|}{ Mode 1} & \multicolumn{2}{|c|}{ Mode 2} & \multicolumn{2}{|c|}{ Mode 3} & \multirow[t]{2}{*}{$\sigma_{\varphi}$} \\
\hline & & & & $w_{1}$ & $\bar{\theta}_{1}\left(^{\circ}\right)$ & $w_{2}$ & $\bar{\theta}_{2}\left({ }^{\circ}\right)$ & $w_{3}$ & $\bar{\theta}_{3}\left({ }^{\circ}\right)$ & \\
\hline ATD & M05(IN02-148) & 0.64 & 223.3 & 0.22 & 8.7 & 0.34 & 11.5 & 0.44 & 16.9 & 12.4 \\
\hline ATD & M06(IN02-148) & 0.64 & 223.4 & 0.21 & 10.9 & 0.29 & 14.4 & 0.50 & 18.0 & 29.8 \\
\hline ATD & M06(IN02-149) & 0.64 & 223.5 & 0.17 & 6.7 & 0.29 & 10.5 & 0.54 & 14.2 & 15.8 \\
\hline ATD & M06(IN03-05) & 0.64 & 210.8 & 0.21 & 10.5 & 0.30 & 12.6 & 0.49 & 14.7 & 8.1 \\
\hline ATD & M06(IN03-06) & 0.64 & 210.6 & 0 & & 0.41 & 11.7 & 0.59 & 13.1 & 5.9 \\
\hline ATD & M06(IN03-067) & 0.64 & 210.5 & 0.02 & 10.2 & 0.39 & 11.6 & 0.59 & 13.7 & 9.3 \\
\hline SD & M06(IN04-40) & 0.84 & 224 & 0 & & 0.16 & 22.9 & 0.84 & 33.6 & 23.5 \\
\hline SD & M06(IN04-44) & 0.84 & 213.1 & 0.27 & 9.8 & 0.05 & 14.0 & 0.68 & 19.6 & 30.0 \\
\hline SD & M06(IN03-11) & 0.84 & 210 & 0.21 & 11.2 & 0.27 & 14.3 & 0.49 & 17.7 & 25.9 \\
\hline MONT & W09 $(200 \mathrm{~nm})$ & 0.25 & 233 & 0 & & 0.08 & 16.1 & 0.92 & 21.1 & 30.0 \\
\hline MONT & W09(200 nm) & 0.25 & 228 & 0 & & 0.06 & 13.3 & 0.94 & 16.4 & 15.9 \\
\hline MONT & W09(200 nm) & 0.25 & 223 & 0 & & 0.10 & 16.0 & 0.90 & 19.8 & 20.8 \\
\hline MONT & W09(200 nm) & 0.25 & 218 & 0 & & 0.11 & 18.5 & 0.89 & 23.7 & 22.0 \\
\hline MONT & W09(400 nm) & 1.00 & 233 & 0 & & 0.05 & 13.4 & 0.95 & 16.6 & 25.6 \\
\hline MONT & W09(400 nm) & 1.00 & 228 & 0 & & 0.10 & 14.2 & 0.90 & 18.5 & 20.0 \\
\hline MONT & W09(400 nm) & 1.00 & 223 & 0 & & 0.08 & 15.8 & 0.92 & 20.1 & 19.9 \\
\hline MONT & W09(400 nm) & 1.00 & 218 & 0 & & 0.07 & 15.2 & 0.92 & 21.7 & 25.0 \\
\hline MONT & W09(800 nm) & 4.01 & 233 & 0 & & 0.13 & 12.1 & 0.87 & 14.5 & 16.5 \\
\hline MONT & W09(800 nm) & 4.01 & 228 & 0 & & 0.12 & 12.8 & 0.88 & 15.2 & 14.3 \\
\hline MONT & W09(800 nm) & 4.01 & 223 & 0 & & 0.14 & 15.0 & 0.86 & 18.6 & 16.4 \\
\hline MONT & W09(800 nm) & 4.01 & 218 & 0 & & 0.04 & 17.8 & 0.96 & 22.6 & 18.3 \\
\hline KAO & W09(200 nm) & 0.25 & 233 & 0 & & 0.08 & 18.4 & 0.92 & 22.9 & 21.8 \\
\hline $\mathrm{KAO}$ & W09(200 nm) & 0.25 & 228 & 0 & & 0.12 & 16.1 & 0.88 & 21.9 & 21.0 \\
\hline $\mathrm{KAO}$ & W09(200 nm) & 0.25 & 223 & 0 & & 0.15 & 15.8 & 0.85 & 21.8 & 19.5 \\
\hline $\mathrm{KAO}$ & W09(200 nm) & 0.25 & 218 & 0 & & 0.14 & 17.2 & 0.86 & 22.5 & 19.6 \\
\hline $\mathrm{KAO}$ & W09(400 nm) & 1.00 & 233 & 0 & & 0.06 & 15.1 & 0.94 & 20.9 & 29.8 \\
\hline $\mathrm{KAO}$ & W09(400 nm) & 1.00 & 228 & 0 & & 0.16 & 14.8 & 0.84 & 19.5 & 30.0 \\
\hline KAO & W09(400 nm) & 1.00 & 223 & 0 & & 0.13 & 16.0 & 0.87 & 20.6 & 30.0 \\
\hline $\mathrm{KAO}$ & W09(400 nm) & 1.00 & 218 & 0 & & 0.08 & 17.4 & 0.92 & 21.2 & 19.2 \\
\hline $\mathrm{KAO}$ & W09(800 nm) & 4.01 & 233 & 0 & & 0.15 & 13.6 & 0.85 & 19.1 & 30.0 \\
\hline $\mathrm{KAO}$ & W09(800 nm) & 4.01 & 228 & 0 & & 0.15 & 13.4 & 0.85 & 17.2 & 21.2 \\
\hline $\mathrm{KAO}$ & W09(800 nm) & 4.01 & 223 & 0 & & 0.10 & 14.8 & 0.90 & 18.3 & 17.6 \\
\hline $\mathrm{KAO}$ & W09(800 nm) & 4.01 & 218 & 0 & & 0.1 & 17.8 & 0.93 & 21.8 & 23.2 \\
\hline OC30 & C11(IN11-20) & 159.4 & 225.1 & 1 & 32.3 & & & & & 29.7 \\
\hline OC30 & C11(IN11-21) & 159.4 & 224.8 & 1 & 35.5 & & & & & 32.6 \\
\hline OC30 & C11(IN11-22) & 159.4 & 224.5 & 1 & 34.6 & & & & & 22.7 \\
\hline
\end{tabular}

Table 3. Summary of average parameters (standard deviation) for the nucleation spectra of Table 2.

\begin{tabular}{lllccccc}
\hline Species & \multicolumn{2}{c}{ Mode 1} & \multicolumn{2}{c}{ Mode 2 } & \multicolumn{2}{c}{ Mode 3 } & $\sigma_{\varphi}$ \\
& $w_{1}$ & $\bar{\theta}_{1}\left({ }^{\circ}\right)$ & $w_{2}$ & $\bar{\theta}_{2}\left({ }^{\circ}\right)$ & $w_{3}$ & $\bar{\theta}_{3}\left({ }^{\circ}\right)$ & \\
\hline ATD & $0.17(0.08)$ & $9.4(1.7)$ & $0.34(0.05)$ & $12.0(1.3)$ & 0.50 & $15.1(1.9)$ & $13.6(8.7)$ \\
SD & $0.24(0.05)$ & $10.5(1.0)$ & $0.16(0.11)$ & $17.1(5.0)$ & 0.60 & $23.6(8.6)$ & $26.1(5.1)$ \\
MONT & & & $0.09(0.03)$ & $15.3(2.0)$ & 0.91 & $19.1(2.9)$ & $20.4(4.6)$ \\
KAO & & & $0.14(0.07)$ & $16.0(1.8)$ & 0.86 & $21.4(3.6)$ & $25.5(4.7)$ \\
ALL DUST & $0.19(0.08)$ & $9.7(1.6)$ & $0.15(0.10)$ & $15.1(2.6)$ & 0.66 & $19.3(3.9)$ & $20.8(7.8)$ \\
OC30 & 1 & $34.2(1.7)$ & & & & & $28.3(5.0)$ \\
\hline
\end{tabular}


Table 4. Suggested parameters for the parameterization of deposition ice nucleation on "generic dust" and soot with low organic carbon content (OC30).

\begin{tabular}{lllccccc}
\hline Species & \multicolumn{2}{c}{ Mode 1 } & \multicolumn{2}{c}{ Mode 2 } & \multicolumn{2}{c}{ Mode 3 } & $\sigma_{\varphi}$ \\
& $w_{1}$ & $\bar{\theta}_{1}\left({ }^{\circ}\right)$ & $w_{2}$ & $\bar{\theta}_{2}\left(^{\circ}\right)$ & $w_{3}$ & $\bar{\theta}_{3}\left({ }^{\circ}\right)$ & \\
\hline DUST & 0.20 & 9.9 & 0.25 & 15.1 & 0.55 & 19.8 & 21.4 \\
SOOT & 1 & 34.2 & & & & & 28.3 \\
\hline
\end{tabular}

and Welti et al. (2009, W09) have reported empirical expressions for the ice nucleation spectra of dust in the deposition mode. M06 studied the ice nucleation properties of Arizona Test Dust (ATD), Saharan Dust (SD) and Arizona Dust (AD) using the AIDA cloud chamber (Möhler et al., 2003) and reported exponential fits to $f_{\mathrm{f}}$. W09 studied the ice nucleation properties of several size-selected dust species using the Zurich Ice Nucleation Chamber (ZINC, Stetzer et al., 2008) and reported sigmoidal fits to $f_{\mathrm{f}}$ for Kaolinite (KAO) and Montmorillonite (MONT).

The expressions reported by M06 and W09 are used to derive the parameters of $\mathcal{N}(\bar{\varphi})$ for the different dust species. Basically, $\bar{\theta}$ (associated with $\bar{\varphi}$ ) and $\sigma_{\varphi}$ in Eqs. (53) and (54) are found for each of the $f_{\mathrm{f}}$ curves reported by M06 and W09 (Table 2). From Seisel et al. (2005), $\Delta g_{\mathrm{d}}=6.5 \times 10^{-20} \mathrm{~J}$ and $\alpha_{\mathrm{c}}=6.3 \times 10^{-2}$. To reduce the parameter space it is assumed that $\sigma_{\varphi}$ is the same for all modes. To minimize the effect of condensation, only experiments with $S_{\mathrm{w}}<0.9$ are used. For M06 it is assumed that $\Delta t_{\exp }=\left(\frac{\mathrm{d} s}{\mathrm{~d} t}\right)^{-1}$ where $\frac{\mathrm{d} s}{\mathrm{~d} t}$ is the measured rate of change of $S_{\mathrm{i}}$ (Möhler et al., 2006). For the W09 data it is assumed that $\Delta t_{\exp }=12 \mathrm{~s}$. M09 reported the value of $\bar{s}_{\mathrm{p}}$ used in their experiments however W09 reported the mean equivalent aerosol size. For the latter, $\bar{s}_{\mathrm{p}}$ is estimated assuming spherical particles and a lognormal size distribution with geometric mean dispersion of 2.5 (cf. Welti et al., 2009, Fig. 3). The values of $\bar{\theta}_{\mathrm{i}}, \sigma_{\varphi}$ and $w_{i}$ are listed in Table 2 and the resulting $f_{\mathrm{f}}$ vs. $S_{\mathrm{i}}$ curves are shown in Figs. 6 and 7. Since the number area distribution was not measured in neither M09 nor W09, area dispersion and surface composition effects are assumed to be combined into $\sigma_{\varphi}$.

The NPDF of KAO and MONT is well represented using bimodal lognormal distributions (Fig. 6, Table 2). Since ATD and SD are mixtures of different materials, three lognormal modes are required to represent their NPDFs (Fig. 7, Table 2). It is however remarkable that such complexity can be described using a few parameters.

Consistent with W09, the spectra derived for the KAO sample with $D_{\text {eq }}=800 \mathrm{~nm}$ tends to reach higher $f_{\mathrm{f}}$ than for $D_{\text {eq }}=200 \mathrm{~nm}$ (Fig. 6). This is however not the case for MONT, which may be a consequence of the slightly lower $\sigma_{\varphi}$ in MONT than in KAO (Table 3) i.e. high $f_{\mathrm{f}}$ is already reached in the MONT sample with $D_{\text {eq }}=200 \mathrm{~nm}$. However, measurement of the number area distribution is required to better constraint $\sigma_{\varphi}$ and understand such behavior.
The average $w_{i}, \sigma_{\varphi}$ and $\bar{\theta}_{i}$ of each mode for the different dust species of Table 2 is presented in Table 3. All dust species exhibit modes in the NPDF centered around $\bar{\theta}_{i} \approx 15^{\circ}$ and $\bar{\theta}_{i} \approx 20^{\circ}$ (although they are centered at slightly lower $\bar{\theta}_{i}$ in ATD, Table 3). ATD and SD exhibit a third mode at $\bar{\theta} \approx 10^{\circ}$. The standard deviation of $\bar{\theta}_{i}$ among all dust species is typically between $10 \%$ and $20 \%$ of the average $\bar{\theta}_{i}$. This consistency suggests that the NPDF of very different dust species may be parameterized using a linear combination of a few lognormal modes. In principle $w_{i}$ for each mode would be linked to the dust source. Such information is however not readily available in most models. A "generic dust" parameterization is therefore formulated by averaging $w_{1}$ and $w_{2}$ between ATD and SD (with $w_{3}=1-w_{1}-w_{2}$ ). The NPDF of dust is assumed to follow a three-modal lognormal distribution with $\bar{\theta}_{i}$ and $\sigma_{\varphi}$ averaged among all the species of Table 3. The parameterization is summarized in Table 4 and shown in Fig. 9.

\section{Soot}

A parameterization for the ice nucleation spectrum of soot can also be derived from experimental data. Few studies however focus on ice nucleation on soot particles (Dymarska et al., 2006; Möhler et al., 2005; DeMott et al., 1999; Gorbunov et al., 2001). Crawford et al. (2011, C11) studied the nucleation properties of soot derived from the combustion of propane. It was found that ice nucleated in the deposition mode on uncoated soot with organic carbon content below $30 \%$ (OC30). Crawford et al. (2011) reported values of $S_{\mathrm{i}}$ at $f_{\mathrm{f}}=0.1 \%$ and $f_{\mathrm{f}}=1 \%$, which are used to constraint Eq. (53). The particle mean surface area, $\bar{s}_{\mathrm{p}}$, is estimated using bulk surface area and density of $32 \mathrm{~m}^{2} \mathrm{~g}^{-1}$ and $1600 \mathrm{Kg} \mathrm{m}^{-3}$, respectively (Popovitcheva et al., 2000), and assuming a lognormal size distribution with geometric mean diameter of $250 \mathrm{~nm}$ and geometric dispersion equal to 2 (Crawford et al., 2011). From Seisel et al. (2005), $\Delta g_{\mathrm{d}}=4.4 \times 10^{-20} \mathrm{~J}$ and $\alpha_{\mathrm{c}}=4.7 \times 10^{-2}$. From the $\mathrm{C} 11$ data, $\Delta t_{\exp }=80 \mathrm{~s}$, corresponding to a cooling rate of about $2 \mathrm{~K} \min ^{-1}$.

Figure 8 shows the derived nucleation spectra for OC 30 soot. $\bar{\theta}$ ranges between $32^{\circ}$ and $36^{\circ}$ and $\sigma_{\varphi}$ between 22 and 32. The latter is slightly larger than the dust average $\sigma_{\varphi}$. Due to the fractal characteristics of soot (Dymarska et al., 2006; Gorbunov et al., 2001), it is possible that surface area dispersion plays a more significant role in determining the NPDF than for dust. The limiting $f_{\mathrm{f}}$ (at $S_{\mathrm{i}}=1.7$ ) is about $25 \%$, in good agreement with the C11 data. The average $\bar{\theta}$ and $\sigma_{\varphi}$ among the spectra of Table 2 (OC30 cases) are used to parameterize $f_{\mathrm{f}}$ (Table 4). The resulting parameterization is shown in Fig. 9; as it is based on limited data its usage is recommended only for exploratory studies. 


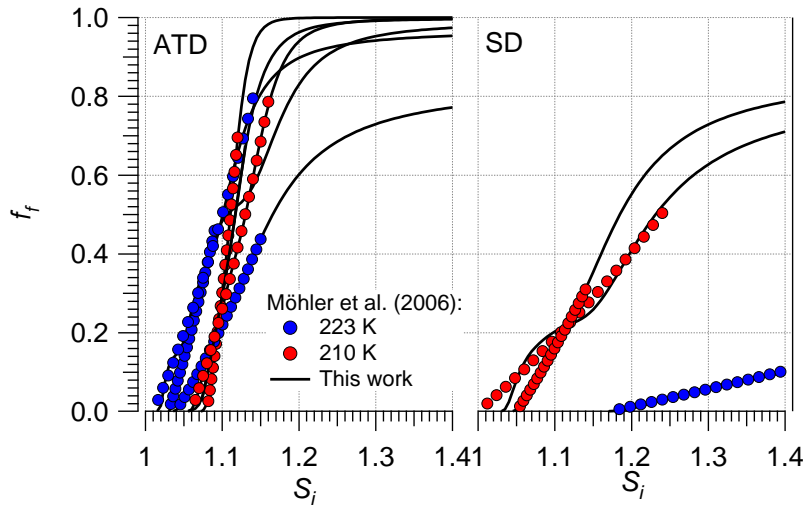

Fig. 7. Heterogeneous ice nucleation spectra in deposition mode for Arizona Test Dust (ATD) and Saharan dust (SD) (Table 2). Lines with the same color indicate runs using different aerosol samples of the same material (Möhler et al., 2006).

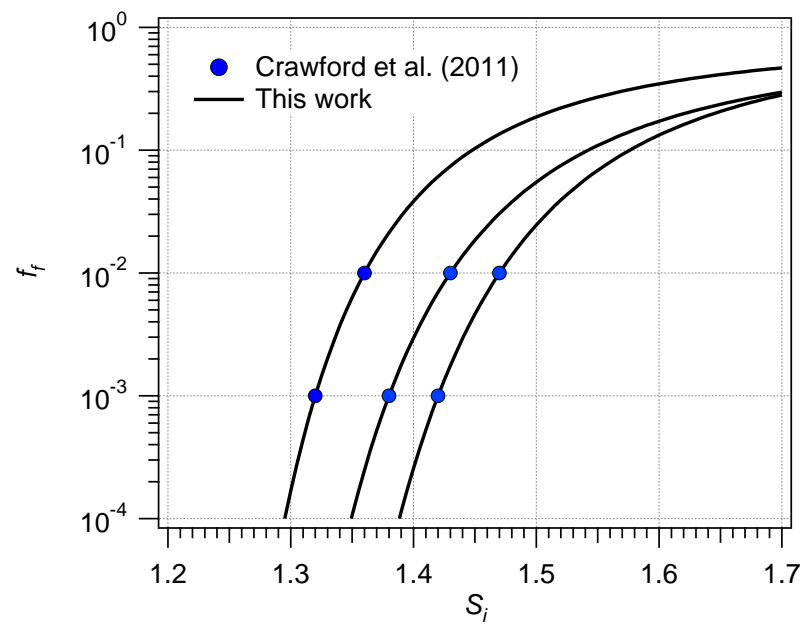

Fig. 8. Heterogeneous ice nucleation spectra in the deposition mode for OC30 soot (Table 2).

\section{Summary and conclusions}

A novel formulation of the ice nucleation spectrum for homogeneous and heterogeneous ice nucleation was developed. This was accomplished by introducing the concepts of ice nucleation coefficient and ice nucleation probability dispersion. It was shown that the NDPF and the aerosol ice nucleation spectra are simply related by Laplace transformation. The new formulation accounts for the dependency of $N_{\mathrm{c}}\left(S_{\mathrm{i}}, T, \mu_{1 \ldots \mathrm{n}}\right)$ on particle size, $T, S_{\mathrm{i}}, u$, and, in the case of heterogeneous ice nucleation, on the distribution of particle area and surface composition. It was applied to the homogeneous freezing of cloud droplets and the heterogeneous ice nucleation on IN in the deposition mode. For the latter, parameterizations of deposition ice nucleation on dust and soot for usage in atmospheric models were developed.
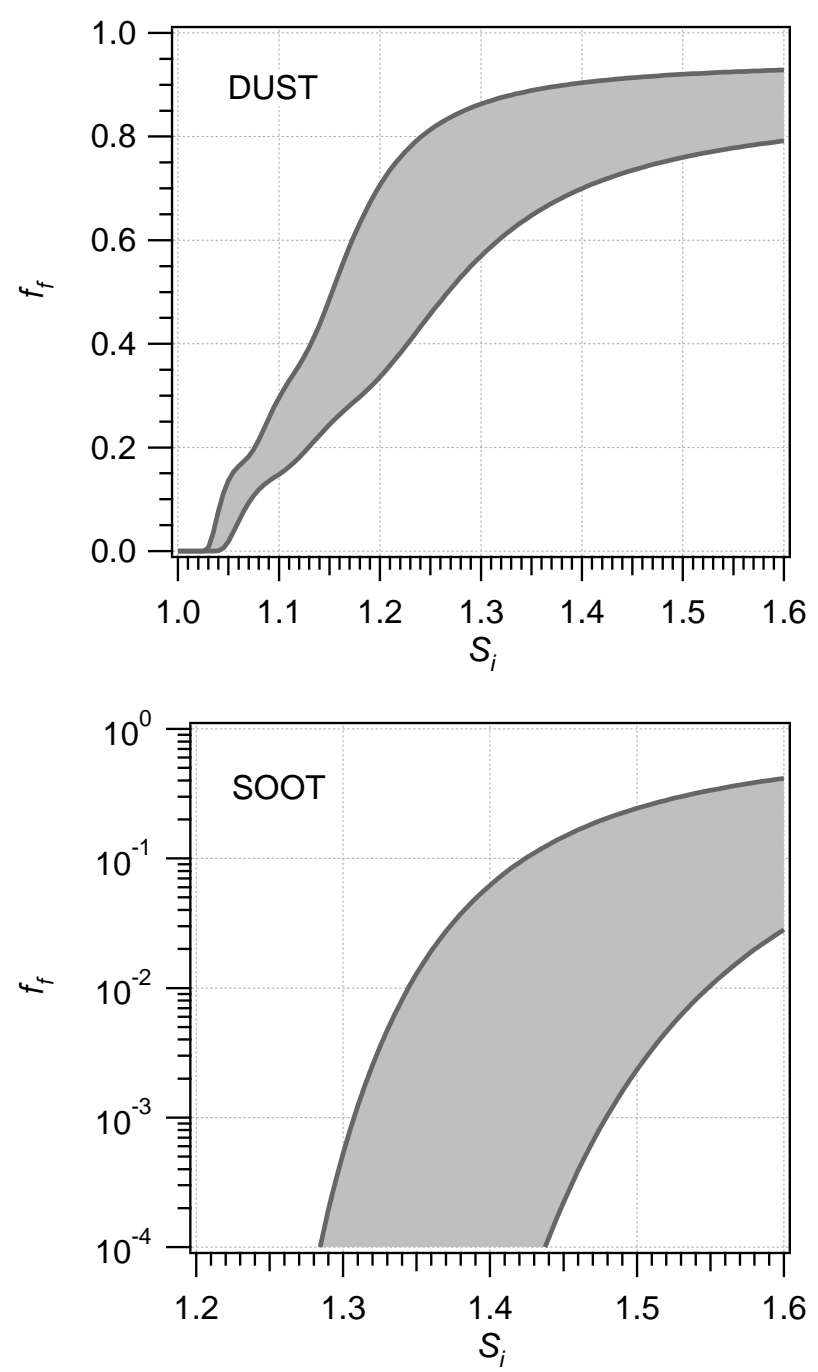

Fig. 9. Parameterization of the heterogeneous ice nucleation spectra for deposition ice nucleation on "generic dust" (DUST) and soot with low organic carbon content (SOOT) (Table 4). The shaded area corresponds to $T=[200-250] \mathrm{K}, u=[0.01-1] \mathrm{m} \mathrm{s}^{-1}$, and $\bar{s}_{\mathrm{p}}=[0.1-100] \mu \mathrm{m}^{2}$.

It was shown that the NPDF for the homogeneous freezing of cloud droplets is determined by the droplet volume distribution and well represented by a gamma distribution. Analysis of $N_{\mathrm{c}}\left(S_{\mathrm{i}}, T, \mu_{1 \ldots \mathrm{n}}\right)$ for this case showed that variation in $D_{\mathrm{p}}$ and $\gamma$ may result in about $2-3 \mathrm{~K}$ variation in $T_{\text {onset }}$. Dispersion in the droplet volume distribution however does not impact $T_{\text {onset }}$ but "stretches" $f_{\mathrm{f}}$ over a wider $T$ interval so that some droplets in the population may freeze at $T$ as low as $228 \mathrm{~K}$. This effect is significant for varr $>0.4$ (Eq. 20) and may have important implications for the cold generation of precipitation as $\mathrm{CCN}$ emissions and entrainment tend to broaden the droplet size distribution.

The theory presented here suggests that the NPDF for heterogeneous ice nucleation on simple materials follows a 
lognormal distribution whereas the NPDF of complex materials can be adequately represented by a sum of lognormal modes. It was also found that NPDFs with support over the whole real axis, like the normal distribution, may introduce unphysical behavior and wrongly imply that values of $\varphi<0$ are accessible to $\mathcal{N}(\bar{\varphi})$. For the lognormal and gamma distributions it was found that $\bar{\varphi}=1$ defines the characteristic ice nucleation properties of the aerosol population. Although this was shown for deposition ice nucleation, it is likely that immersion and condensation freezing display the same behavior as Eq. (36) is common to different heterogeneous nucleation modes.

Singular and stochastic behavior were reproduced using the new formulation of $N_{\mathrm{c}}\left(S_{\mathrm{i}}, T, \mu_{1 \ldots \mathrm{n}}\right)$. In deposition ice nucleation $S_{\mathrm{i}}, \bar{\theta}, u, T, \bar{s}_{\mathrm{p}}$, and $\sigma_{\varphi}$ play a role defining $f_{\mathrm{f}}$, however highly efficient IN $\left(\theta<10^{\circ}\right)$ are only sensitive to variation in $S_{\mathrm{i}}$, and $\bar{\theta}$. This is however not the case for less efficient IN for which changes in the cooling rate (expressed through the dependency of $f_{\mathrm{f}}$ on $u$ ) and variability in surface characteristics (expressed through the dependency of $f_{\mathrm{f}}$ on $\left.\sigma_{\varphi}\right)$ impact $f_{\mathrm{f}}$. Thus, ice nucleation on IN with high $\bar{\theta}$ show features commonly identified with stochastic behavior while the ice nucleation spectrum of efficient IN (low $\bar{\theta}$ ) tends be consistent with singular behavior. This implies that ice nucleation on materials with multimodal NPDF would likely exhibit both, singular and stochastic characteristics.

It was found that even if $N_{\mathrm{c}}\left(S_{\mathrm{i}}, T, \mu_{1 \ldots \mathrm{n}}\right)$ is affected by variation in the cooling rate it may still be insensitive to temporal effects. This is because temporal effects may be masked by surface variability and by high or low nucleation rates at the experimental conditions employed. However high surface variability will not always lead to weak temporal effects as they also depend on the $S_{\mathrm{i}}$ trajectory followed in an experiment. It was also shown that even if temporal effects on $N_{\mathrm{c}}\left(S_{\mathrm{i}}, T, \mu_{1 \ldots \mathrm{n}}\right)$ are significant, $N_{\mathrm{c}}\left(S_{\mathrm{i}}, T, \mu_{1 \ldots \mathrm{n}}\right)$ may still be insensitive to variation in the cooling rate. Both cooling rate independence and constancy of $f_{\mathrm{f}}$ over time were reproduced using a time-dependent, stochastic approach. Thus, this behavior cannot be considered prove of the singular hypothesis and measurement of $f_{\mathrm{f}}$ alone cannot discriminate between singular and stochastic ice nucleation.

The temporal dependency of $f_{\mathrm{f}}$ shown in Fig. 4 suggested that IN measurements in cloud chambers with short residence time $(\sim 10-20$ s) would tend to underestimate the IN concentration. However it must be noticed that in this work it was assumed that active sites can be represented as adsorption sites with high $J_{\text {het }}$. Nucleation on active sites must admit a time-dependent representation, however there is no guarantee that it can be approximated through $J_{\text {het }}$. Thus the temporal dependency of $f_{\mathrm{f}}$ may differ from the results of Fig. 4 if active sites that cannot be represented as adsorption surfaces are present in the IN population.

Comparison of derived $N_{\mathrm{c}}\left(S_{\mathrm{i}}, T, \mu_{1 \ldots \mathrm{n}}\right)$ against empirical data (Möhler et al., 2006; Welti et al., 2009) showed that the NPDF of simple dust species like Kaolinite and Montmo- rillonite can be accurately represented by bimodal NPDFs whereas complex mixtures like Arizona Test Dust and Saharan Dust are well represented by three-modal NPDFs. It is however remarkable that for all of the dust species studied these modes are consistently located around $\bar{\theta}_{1} \approx 10^{\circ}$, $\bar{\theta}_{2} \approx 15^{\circ}$, and $\bar{\theta}_{3} \approx 20^{\circ}$, suggesting that the NPDF of dust from different sources can be represented by a linear combination of few lognormal modes. This feature was used to generate a parameterization of deposition ice nucleation on "generic dust". Further measurements of $N_{\mathrm{c}}\left(S_{\mathrm{i}}, T, \mu_{1 \ldots \mathrm{n}}\right)$ covering the full range of $f_{\mathrm{f}}$ (i.e. $f_{\mathrm{f}}=[0-1]$ ) are required to elucidate the fundamental reasons behind such behavior.

The nucleation spectrum of soot was also investigated. It was found that deposition ice nucleation on low organic content soot is well represented using a single-mode lognormal NPDF with $\bar{\theta}=34.2^{\circ}$. The limiting $f_{\mathrm{f}}$ of $25 \%$ found by Crawford et al. (2011) was in good agreement with the predictions of Eq. (53). A parameterization was proposed for usage in atmospheric models, however further experimental measurements are required to better represent the ice nucleation properties of soot.

The theory presented here suggests that inferring the aerosol ice nucleation properties from measurement of $S_{\mathrm{i}, \text { onset }}$ at $f_{\mathrm{f}} \approx 0.01$ may carry significant error. First, Fig. 3 shows that $S_{\mathrm{i} \text {,onset }}$ is strongly impacted by $\sigma_{\varphi}$ so that it may vary between samples of the same material or between freezing cycles. Second, $S_{\mathrm{i}, \text { onset }}$ represents the ice nucleation properties associated with the most efficient mode in the NPDF, which may be the less abundant (Table 2). Finally $S_{\mathrm{i} \text {,onset }}$ does not provide information on $\sigma_{\varphi}$ which may impact the inferred $\bar{\theta}$ (Fig. 5). These effects can be reduced by measuring $S_{\mathrm{i}, \text { med }}$ at $f_{\mathrm{f}} \approx 0.5$ (corresponding to $\bar{\varphi} \approx 1$ ). Ideally, it is best to determine the $f_{\mathrm{f}}$ vs. $S_{\mathrm{i}}$ curve which would also indicate the existence of multiple modes in the NPDF. For this, it is also important to measure the aerosol number area distribution instead of the number size distribution as it is the former, not the latter, what determines $\bar{\varphi}$ and $\sigma_{\varphi}$, hence $N_{\mathrm{c}}\left(S_{\mathrm{i}}, T, \mu_{1 \ldots \mathrm{n}}\right)$.

Although this work focuses on heterogeneous nucleation in the deposition mode, it is readily suited for other nucleation modes. Heterogeneous freezing in the immersion and condensation modes share many features with deposition ice nucleation. Still, water adsorption on the particle surface (e.g. Seisel et al., 2005; Kumar et al., 2009), the effect of the solute on the interfacial tension, and the droplet size distribution may play a role in defining $f_{\mathrm{f}}$. This will be detailed in a companion study.

In a general sense, the NPDF can be understood as the combined distribution of ice nucleation efficiency and the area over which that efficiency maintains. Although the NPDF is fundamentally different from the contact angle and the active site distributions, they can be recovered from the NPDF when either the contact angle or the active site area is constant in the aerosol population. Thus using the theory presented here the results of previous mechanistic approaches 
can be understood within a more comprehensive framework, which at the same time is casted in a simple mathematical form requiring fewer parameters, and unlike fits to experimental results assigns precise physical meaning to such parameters. This work provides a physically-based method to reconcile theory, laboratory measurements and field campaign data, within a unified ice nucleation framework suitable for atmospheric modeling studies.

\section{List of symbols}

$\alpha \quad$ Parameter of the gamma distribution

$\alpha_{\mathrm{s}} \quad \frac{g \Delta H_{\mathrm{s}} m_{\mathrm{w}}}{c_{\mathrm{p}} k T^{2}}-\frac{g m_{\mathrm{a}}}{k T}$

$\alpha_{\mathrm{c}} \quad$ Water vapor mass accommodation

coefficient

$\beta \quad$ Parameter of the gamma distribution

$\beta_{\mathrm{h}} \quad$ Rate at which water molecules are incorporated

into the critical ice cluster

$\gamma \quad$ Cooling rate, $-\frac{\mathrm{d} T}{\mathrm{~d} t}$

$\Delta g_{\mathrm{d}} \quad$ Desorption energy of the water molecules from the particle's surface

$\Delta g_{\mathrm{g}} \quad$ Energy of formation of the ice germ

$\Delta H_{\mathrm{s}} \quad$ Latent heat of sublimation of ice

$\Delta t_{\exp } \quad$ Experimental observation time

$\epsilon_{\mathrm{T}} \quad$ Temperature perturbation

$\epsilon_{\mathrm{S}_{\mathrm{i}}} \quad$ Perturbation in $S_{\mathrm{i}}$

$\epsilon_{\mathrm{S}_{\mathrm{w}}} \quad$ Perturbation in $S_{\mathrm{w}}$

$\theta \quad$ Local contact angle between the solid surface

and the ice germ

$\theta_{\mathrm{p}} \quad$ Particle effective contact angle

$\bar{\theta} \quad$ Characteristic contact angle associated with $\bar{\varphi}$

$\mu_{i} \quad i$-th moment of the distribution of aerosol number concentration

v $\quad 1-\frac{1}{7 \text { varr }}$

$\xi \quad \frac{\varphi}{\bar{\varphi}}$

$\rho_{\text {as }} \quad$ Surface density of active sites

$\sigma_{\varphi} \quad$ Ice nucleation dispersion coefficient

$\sigma_{\mathrm{i} / \mathrm{v}} \quad$ Surface tension of ice

$\tau_{\text {nuc }} \quad$ Timescale of nucleation

$\varphi \quad$ Ice nucleation coefficient

$\bar{\varphi} \quad$ Characteristic ice nucleation coefficient

$A \quad \frac{\alpha_{c}}{\sqrt{f}} \frac{p_{\mathrm{v}}^{2} v_{\mathrm{w}}}{m_{\mathrm{w}} k T v_{\mathrm{s}}} \sqrt{\frac{\sigma_{\mathrm{i} / \mathrm{v}}}{k T}} \exp \left(\frac{\Delta g_{\mathrm{d}}}{k T}\right)$

$c_{1, \mathrm{~s}} \quad$ Surface concentration of water molecules

$c_{\mathrm{p}} \quad$ Heat capacity of air

$D_{\mathrm{p}} \quad$ Equivalent droplet size

$f \quad$ Compatibility parameter

$f_{\mathrm{f}} \quad$ Ice nucleation fraction

$g \quad$ Acceleration of gravity

$J_{\text {het }} \quad$ Heterogeneous ice nucleation coefficient associated with $\bar{\varphi}$

\begin{tabular}{|c|c|}
\hline$J_{\text {het, } \mathrm{k}}$ & $\begin{array}{l}\text { Local heterogeneous ice nucleation } \\
\text { coefficient }\end{array}$ \\
\hline$J_{\text {het, } \mathrm{p}}$ & $\begin{array}{l}\text { Particle effective heterogeneous ice } \\
\text { nucleation coefficient }\end{array}$ \\
\hline$J_{\text {hom }}$ & Homogeneous ice nucleation coefficient \\
\hline$k$ & Boltzmann constant \\
\hline$m_{\mathrm{a}}$ & Molecular mass of air \\
\hline$m_{\mathrm{W}}$ & Mass of a water molecule \\
\hline$M$ & $\begin{array}{l}\text { Number of lognormal modes } \\
\text { in the NPDF }\end{array}$ \\
\hline$N_{\mathrm{a}}$ & Aerosol number concentration \\
\hline$N_{\mathrm{c}}\left(S_{\mathrm{i}}, T, \mu_{1, n}\right)$ & Ice Nucleation Spectrum \\
\hline$n_{\mathrm{g}}^{\circ}$ & $\begin{array}{l}\text { Number of water molecules in the ice } \\
\text { germ at liquid water saturation }\end{array}$ \\
\hline$n(\varphi)$ & Probability distribution function of $\varphi$ \\
\hline$n(\xi)$ & $\begin{array}{l}\text { Nucleation Probability Dispersion } \\
\text { Function (NPDF) }\end{array}$ \\
\hline $\mathcal{N}(\bar{\varphi})$ & Laplace transform of $n(\xi)$ \\
\hline$P_{\mathrm{f}}$ & Probability of ice nucleation \\
\hline$p_{\mathrm{s}, \mathrm{w}}, p_{\mathrm{s}, \mathrm{i}}$ & $\begin{array}{l}\text { Liquid water and ice saturation } \\
\text { vapor pressures at } T \text {, respectively }\end{array}$ \\
\hline$p_{\mathrm{v}}$ & Water vapor pressure \\
\hline$r_{\mathrm{g}}$ & Ice germ size \\
\hline$r_{\mathrm{g}}^{\circ}$ & Value of $r_{\mathrm{g}}$ at $S_{\mathrm{w}}=1$ \\
\hline$S_{\mathrm{i}}^{8}$ & Saturation ratio with respect to ice \\
\hline$S_{\mathrm{W}}$ & $\begin{array}{l}\text { Saturation ratio with respect to } \\
\text { liquid water }\end{array}$ \\
\hline$S_{\mathrm{w}}^{\text {isat }}$ & $p_{\mathrm{s}, \mathrm{i}} / p_{\mathrm{s}, \mathrm{w}}$ \\
\hline$s_{\mathrm{p}}$ & Particle surface area \\
\hline$t^{p}$ & Time \\
\hline$T$ & Temperature \\
\hline$T_{0}$ & $273 \mathrm{~K}$ \\
\hline$u$ & Vertical wind velocity \\
\hline varr & $\begin{array}{l}\text { Variance of the droplet volume } \\
\text { distribution }\end{array}$ \\
\hline$v_{\mathrm{p}}$ & Droplet volume \\
\hline$v_{\mathrm{S}}$ & Molecular frequency of vibration \\
\hline$v_{\mathrm{w}}$ & Volume of a water molecule \\
\hline$w_{i}$ & $\begin{array}{l}\text { Weight of the } i \text {-th lognormal mode in } \\
\text { the NPDF }\end{array}$ \\
\hline$Z_{\text {het }}$ & Zeldovich factor \\
\hline
\end{tabular}

Acknowledgements. This work was supported by the NASA Modeling, Analysis and Prediction program under WBS 802678.02.17.01.07. The author also thanks Athanasios Nenes, Ricardo Morales and Sara Lance for their helpful comments and discussion.

Edited by: C. Hoose 


\section{References}

Austin, P., Wang, Y., Kujala, V., and Pincus, R.: Precipitation in Stratocumulus Clouds: Observational and Modeling Results, J. Atmos. Sci., 52, 2329-2352, doi:10.1175/15200469(1995)052<2329:PISCOA>2.0.CO;2, 1995.

Barahona, D. and Nenes, A.: Parameterization of cirrus formation in large scale models: Homogeneous nucleation, J. Geophys. Res., 113, D11211, doi:10.1029/2007JD009355, 2008.

Barahona, D. and Nenes, A.: Parameterizing the competition between homogeneous and heterogeneous freezing in ice cloud formation - polydisperse ice nuclei, Atmos. Chem. Phys., 9, 59335948, doi:10.5194/acp-9-5933-2009, 2009.

Barahona, D., Rodriguez, J., and Nenes, A.: Sensitivity of the global distribution of cirrus Ice crystal concentration to heterogeneous freezing, J. Geophys. Res., 15, D23213, doi:10.1029/2010JD014273, 2010.

Broadley, S. L., Murray, B. J., Herbert, R. J., Atkinson, J. D., Dobbie, S., Malkin, T. L., Condliffe, E., and Neve, L.: Immersion mode heterogeneous ice nucleation by an illite rich powder representative of atmospheric mineral dust, Atmos. Chem. Phys., 12, 287-307, doi:10.5194/acp-12-287-2012, 2012.

Chen, J.-P., Hazra, A., and Levin, Z.: Parameterizing ice nucleation rates using contact angle and activation energy derived from laboratory data, Atmos. Chem. Phys., 8, 7431-7449, doi:10.5194/acp-8-7431-2008, 2008.

Connolly, P. J., Möhler, O., Field, P. R., Saathoff, H., Burgess, R., Choularton, T., and Gallagher, M.: Studies of heterogeneous freezing by three different desert dust samples, Atmos. Chem. Phys., 9, 2805-2824, doi:10.5194/acp-9-2805-2009, 2009.

Crawford, I., Möhler, O., Schnaiter, M., Saathoff, H., Liu, D., McMeeking, G., Flynn, M., Bower, K. N., Connolly, P. J., Gallagher, M. W., and Coe, H.: Studies of propane flame soot acting as heterogeneous ice nuclei in conjunction with single particle soot photometer measurements, Atmos. Chem. Phys., 11, 95499561, doi:10.5194/acp-11-9549-2011, 2011.

DeMott, P., Meyers, M., and Cotton, R.: Parameterization and impact of ice initiation processes relevant to numerical model simulations of cirrus clouds, J. Atmos. Sci., 51, 77-90, 1994.

DeMott, P., Chen, Y., Kreidenweis, S., Rogers, D., and Sherman, D.: Ice formation by black carbon particles, Geophys. Res. Lett., 26, 2429-2432, 1999.

DeMott, P., Cziczo, D., Prenni, A., Murphy, D., Kreidenweis, S., Thompson, D., Borys, R., and Rogers, D.: Measurements of the concentration and composition of nuclei for cirrus formation, $\mathrm{P}$. Natl. Acad. Sci. USA, 100, 14655-14660, 2003 a.

DeMott, P., Sassen, K., Poellot, M., Baumgardner, D., Rogers, D., Brooks, S., Prenni, A., and Kreidenweis, S.: African dust aerosols as atmospheric ice nuclei, Geophys. Res. Lett., 30, 1732, doi:10.1029/2003GL017410, 2003b.

DeMott, P. J., Prenni, A. J., Liu, X., Kreidenweis, S. M., Petters, M. D., Twohy, C. H., Richardson, M. S., Eidhammer, T., and Rogers, D. C.: Predicting global atmospheric ice nuclei distributions and their impacts on climate, P. Natl. Acad. Sci., 107, 11217-11222, doi:10.1073/pnas.0910818107, 2010.

Diehl, K., Simmel, M., and Wurzler, S.: Effects of drop freezing on microphysics of an ascending cloud parcel under biomass burning conditions, Atmos. Environ., 41, 303-314, 2007.

Dymarska, M., Murray, B., Sun, L., Eastwood, M., Knopf, D., and Bertram, A.: Deposition ice nucleation on soot at temper- atures relevant for the lower troposphere, J. Geophys. Res., 111, D04204; doi:10.1029/2005JD006627, 2006.

Eastwood, M., Cremel, S., Gehrke, C., Girard, E., and Bertram, A. Ice nucleation on mineral dust particles: Onset conditions, nucleation rates and contact angles, J. Geophys. Res., 113, D22203, doi:10.1029/2008JD010639, 2008.

Eidhammer, T., DeMott, P., and Kreidenweis, S.: A comparison of heterogeneous ice nucleation parameterizations using a parcel model framework, J. Geophys. Res., 114, D06202, doi:10.1029/2008JD011095, 2009.

Fletcher, H.: Active sites and ice crystal nucleation, J. Atmos. Sci., 26, 1266-1271, 1969.

Gayet, J., Ovarlez, J., Shcherbakov, V., Ström, J., Schumann, U., Minikin, A., Auriol, F., Petzold, A., and Monier, M.: Cirrus cloud microphysical and optical properties at southern and northern midlatitudes during the INCA experiment, J. Geophys. Res., 109, D20206, doi:10.1029/2004JD004803, 2004.

Gorbunov, B., Baklanov, A., Kakutkina, N., Windsor, H. L., and Toumi, R.: Ice nucleation on soot particles, J. Aerosol Sci., 32, 199-215, doi:10.1016/S0021-8502(00)00077-X, 2001.

Hoose, C., Kristjansson, J., Chen, J.-C., and Hazra, A.: A classical-theory-based parameterization of heterogeneous ice nucleation by mineral dust, soot, and biological particles in a global climate model, J. Atmos. Sci., 67, 2483-2503, doi:10.1175/2010JAS3425.1, 2010.

IPCC: Climate change 2007: the physical basis. Contribution of working group I to the fourth assessment report of the Intergovernmental Panel on Climate Change., Cambridge University Press, Cambridge, United Kingdom and New York, NY, USA., 2007.

Kanji, Z., Florea, O., and Abbatt, J.: Ice formation via deposition nucleation on mineral dust and organics: dependence of onset relative humidity on total particulate surface area, Environ. Res. Lett., 3, 025004, doi:10.1088/1748-9326/3/2/025004, 2008.

Kärcher, B., Hendricks, J., and Lohmann, U.: Physically based parameterization of cirrus cloud formation for use in global atmospheric models, J. Geophys. Res., 111, D01205, doi:10.1029/2005JD006219, 2006.

Kashchiev, D.: Nucleation: basic theory with applications, Butterworth Heinemann, 2000.

Khvorostyanov, V. and Curry, J.: The theory of ice nucleation by heterogeneous freezing of deliquescent mixed CCN. Part I: critical radius, energy and nucleation rate, J. Atmos. Sci., 61, 26762691, 2004.

Khvorostyanov, V. and Sassen, K.: Toward the theory of homogeneous nucleation and its parameterization for cloud models, Geophys. Res. Lett., 25, 3155-3158, 1998.

Koop, T., Luo, B., Tslas, A., and Peter, T.: Water activity as the determinant for homogeneous ice nucleation in aqueous solutions, Nature, 406, 611-614, 2000.

Kumar, P., Sokolik, I. N., and Nenes, A.: Parameterization of cloud droplet formation for global and regional models: including adsorption activation from insoluble CCN, Atmos. Chem. Phys., 9, 2517-2532, doi:10.5194/acp-9-2517-2009, 2009.

Liu, X. and Penner, J.: Ice nucleation parameterization for global models, Meteorol. Z., 14, 499-514, 2005.

Lohmann, U.: A glaciation indirect aerosol effect caused by soot aerosols, Geophys. Res. Lett, 29, 1052, doi:10.1029/2001GL014357, 2002. 
Lohmann, U. and Diehl, K.: Sensitivity studies of the importance of dust ice nuclei for the indirect aerosol effect of stratiform mixedphase clouds, J. Atmos. Sci., 63, 968-982, 2006.

Lohmann, U. and Feichter, J.: Global indirect aerosol effects: a review, Atmos. Chem. Phys., 5, 715-737, doi:10.5194/acp-5-7152005, 2005.

Lüönd, F., Stetzer, O., Welti, A., and Lohmann, U.: Experimental study on the ice nucleation ability of size-selected kaolinite particles in the immersion mode, J. Geophys. Res., 115, D14201, doi:10.1029/2009JD012959, 2010.

Määttänen, A., Vehkamäki, H., Lauri, A., Merikallio, S., Kauhanen, J., Savijärvi, H., and Kulmala, M.: Nucleation studies in the Martian atmosphere, J. Geophys. Res., 110, E02002, doi:10.1029/2004JE002308, 2005.

Marcolli, C., Gedamke, S., Peter, T., and Zobrist, B.: Efficiency of immersion mode ice nucleation on surrogates of mineral dust, Atmos. Chem. Phys., 7, 5081-5091, doi:10.5194/acp-7-50812007, 2007.

Medhi, J.: Stochastic processes, J. Wiley, New Delhi, India, 1994.

Meyers, M., DeMott, P., and Cotton, R.: New primary icenucleation parameterization in an explicit cloud model, J. Appl. Meteorol., 31, 708-721, 1992.

Möhler, O., Stetzer, O., Schaefers, S., Linke, C., Schnaiter, M., Tiede, R., Saathoff, H., Krämer, M., Mangold, A., Budz, P., Zink, P., Schreiner, J., Mauersberger, K., Haag, W., Kärcher, B., and Schurath, U.: Experimental investigation of homogeneous freezing of sulphuric acid particles in the aerosol chamber AIDA, Atmos. Chem. Phys., 3, 211-223, doi:10.5194/acp-3-211-2003, 2003.

Möhler, O., Linke, C., Saathoff, H., Schnaiter, M., Wagner, R., Mangold, A., Krämer, M., and Schurath, U.: Ice nucleation on flame soot aerosol of different organic carbon content, Meteorol. Z., 14, 477-484, doi:10.1127/0941-2948/2005/0055, 2005.

Möhler, O., Field, P. R., Connolly, P., Benz, S., Saathoff, H., Schnaiter, M., Wagner, R., Cotton, R., Krämer, M., Mangold, A., and Heymsfield, A. J.: Efficiency of the deposition mode ice nucleation on mineral dust particles, Atmos. Chem. Phys., 6, 3007-3021, doi:10.5194/acp-6-3007-2006, 2006.

Murphy, D. and Koop, T.: Review of the vapour pressures of ice and supercooled water for atmospheric applications, Q. J. Roy. Meteorol. Soc., 131, 1539-1565, 2005.

Murray, B. J., Broadley, S. L., Wilson, T. W., Atkinson, J. D., and Wills, R. H.: Heterogeneous freezing of water droplets containing kaolinite particles, Atmos. Chem. Phys., 11, 4191-4207, doi:10.5194/acp-11-4191-2011, 2011.

Niedermeier, D., Shaw, R. A., Hartmann, S., Wex, H., Clauss, T., Voigtländer, J., and Stratmann, F.: Heterogeneous ice nucleation: bridging stochastic and singular freezing behavior, Atmos. Chem. Phys., 11, 8767-8775, doi:10.5194/acp-11-8767-2011, 2011.

Phillips, V., DeMott, P., and Andronache, C.: An empirical parameterization of heterogeneous ice nucleation for multiple chemical species of aerosol, J. Atmos. Sci., 65, 2757-2783, doi:10.1175/2007JAS2546.1, 2008.

Popovitcheva, O. B., Persiantseva, N. M., Trukhin, M. E., Rulev, G. B., Shonija, N. K., Buriko, Y. Y., Starik, A. M., Demirdjian, B., Ferry, D., and Suzanne, J.: Experimental characterization of aircraft combustor soot: Microstructure, surface area, porosity and water adsorption, Phys. Chem. Chem. Phys., 2, 4421-4426,
doi:10.1039/B004345L, 2000.

Pratt, K., DeMott, P., French, J., Wang, Z., Westphal, D., Heymsfield, A., Twohy, C., Prenni, A., and Prather, K.: In situ detection of biological particles in cloud ice-crystals, Nature Geosci., 2, 398-401, 2009.

Prenni, A., Petters, M., Kreidenweis, S., Heald, C., Martin, S., Artaxo, P., Garland, R., Wollny, A., and Pöschl, U.: Relative roles of biogenic emissions and Saharan dust as ice nuclei in the Amazon basin, Nature Geosci., 2, 402-405, 2009.

Pruppacher, H. and Klett, J.: Microphysics of clouds and precipitation, Kluwer Academic Publishers, Boston, MA, 2nd edn., 1997.

Ramanathan, V., Crutzen, P., Kiehl, J., and Rosenfeld, D.: Aerosols, climate, and the hydrological cycle, Science, 294, 2119-2124, 2001.

Rosenfeld, D. and Woodley, W. L.: Deep convective clouds with sustained supercooled liquid water down to $-37.5^{\circ} \mathrm{C}$, Nature, 405, 440-442, doi:10.1038/35013030, 2000.

Rossberg, A.: Laplace transforms of probability distributions and their inversions are easy on logarithmic scales, J. App. Prob., 45, 531-541, 2008.

Seinfeld, J. H. and Pandis, S. N.: Atmospheric Chemistry and Physics, John Wiley and Sons, New York, NY, USA, 1998.

Seisel, S., Pashkova, A., Lian, Y., and Zellner, R.: Water uptake on mineral dust and soot: A fundamental view of the hydrophilicity of atmospheric particles?, Faraday Discuss., 130, 437-451, doi:10.1039/B417449F, 2005.

Shortle, J. F., Fischer, M. J., Gross, D., and Masi, D. M. B.: Using the transform approximation method to analyze queues with heavy-tailed service, J. Probab. Statist. Sci, 1, 17-30, 2003.

Stetzer, O., Baschek, B., Lüönd, F., and Lohmann, U.: The Zurich ice nucleation chamber (ZINC)-A New instrument to investigate atmospheric ice formation, Aerosol. Sci. Technol., 42, 64-74, 2008.

Vali, G.: Freezing rate due to heterogeneous nucleation, J. Atmos. Sci., 51, 1843-1856, 1994.

Vali, G.: Repeatability and randomness in heterogeneous freezing nucleation, Atmos. Chem. Phys., 8, 5017-5031, doi:10.5194/acp-8-5017-2008, 2008.

Vehkamäki, H., Määttänen, A., Lauri, A., Napari, I., and Kulmala, M.: Technical Note: The heterogeneous Zeldovich factor, Atmos. Chem. Phys., 7, 309-313, doi:10.5194/acp-7-309-2007, 2007.

Wang, B. and Knopf, D. A.: Heterogeneous ice nucleation on particles composed of humic-like substances impacted by $\mathrm{O}_{3}$, J. Geophys. Res., 116, D03205, doi:10.1029/2010JD014964, 2011.

Welti, A., Lüönd, F., Stetzer, O., and Lohmann, U.: Influence of particle size on the ice nucleating ability of mineral dusts, Atmos. Chem. Phys., 9, 6705-6715, doi:10.5194/acp-9-6705-2009, 2009.

Zimmermann, F., Weinbruch, S., Schütz, L., Hofmann, H., Ebert, M., Kandler, K., and Worringen, A.: Ice nucleation properties of the most abundant mineral dust phases, J. Geophys. Res., 113, D23204, doi:10.1029/2008JD010655, 2008.

Zobrist, B., Koop, T., Luo, B., Marcolli, C., and Peter, T.: Heterogeneous ice nucleation rate coefficient of water droplets coated by a nonadecanol monolayer, J. Phys. Chem. C, 111, 2149-2155, 2007. 